\title{
Review Article \\ The Impact of Ghrelin in Metabolic Diseases: An Immune Perspective
}

\author{
Jéssica Aparecida da Silva Pereira, ${ }^{1,2}$ Felipe Corrêa da Silva, ${ }^{1}$ and \\ Pedro Manoel Mendes de Moraes-Vieira ${ }^{1,2}$ \\ ${ }^{1}$ Laboratory of Immunometabolism, Department of Genetics, Evolution and Bioagents, Institute of Biology, University of Campinas, \\ São Paulo, SP, Brazil \\ ${ }^{2}$ Department of Immunology, Institute of Biomedical Science, University of São Paulo, São Paulo, SP, Brazil
}

Correspondence should be addressed to Pedro Manoel Mendes de Moraes-Vieira; pmvieira@unicamp.br

Received 7 May 2017; Revised 7 July 2017; Accepted 31 July 2017; Published 7 September 2017

Academic Editor: Ed Randell

Copyright ( 2017 Jéssica Aparecida da Silva Pereira et al. This is an open access article distributed under the Creative Commons Attribution License, which permits unrestricted use, distribution, and reproduction in any medium, provided the original work is properly cited.

\begin{abstract}
Obesity and insulin resistance have reached epidemic proportions. Obesogenic conditions are associated with increased risk for the development of other comorbidities and obesity-related diseases. In metabolic disorders, there is chronic low-grade inflammation induced by the activation of immune cells, especially in metabolic relevant organs such as white adipose tissue (WAT). These immune cells are regulated by environmental and systemic cues. Ghrelin is a peptide secreted mainly by X/A-like gastric cells and acts through the growth hormone secretagogue receptor (GHS-R). This receptor is broadly expressed in the central nervous system (CNS) and in several cell types, including immune cells. Studies show that ghrelin induces an orexigenic state, and there is increasing evidence implicating an immunoregulatory role for ghrelin. Ghrelin mainly acts on the innate and adaptive immune systems to suppress inflammation and induce an anti-inflammatory profile. In this review, we discuss the immunoregulatory roles of ghrelin, the mechanisms by which ghrelin acts and potential pharmacological applications for ghrelin in the treatment of obesity-associated inflammatory diseases, such as type 2 diabetes (T2D).
\end{abstract}

\section{Introduction}

The incidence of obesity and insulin resistance has increased in recent years. The World Health Organization (WHO) estimates that approximately 600 million adult people are obese [1]. Obesity directly impacts the economy and the quality of life of affected patients [2,3]. Obesity is a disease with multifactorial origins and is characterized by excessive lipid accumulation in white adipose tissue (WAT), is promoted by the imbalance between caloric intake and energy expenditure $[4,5]$, and has harmful consequences to the individual [6]. Obesity is a risk factor for the development of other diseases, such as type 2 diabetes (T2D), metabolic syndrome, cardiovascular diseases, atherosclerosis, and several types of cancer [6-10].

WAT is a critical organ that contributes to host metabolism. Several cell types reside in WAT that regulate WAT and systemic homeostasis, such as adipocytes and preadipocytes, fibroblasts, macrophages, $\mathrm{T}$ lymphocytes, and among several other immune and nonimmune cells [11-15]. During obesity, immune alterations are observed in response to WAT expansion, which lead to a low-grade chronic inflammation. This inflammatory response is induced by changes in the recruitment of new leukocytes and also by changes in the function and activation status of adipose tissue resident macrophages (ATMs) and other leukocytes $[6,16,17]$. The immune changes that occur in WAT are characterized by the reduction of anti-inflammatory cytokines, such as interleukin 10 (IL-10), and upregulation of proinflammatory cytokines, such as tumor necrosis factor- $\alpha$ (TNF- $\alpha$ ). This leads to the inhibition of the insulin-signaling pathway, which results in systemic insulin resistance [17].

Disruption of adipose tissue (AT) homeostasis and the induction of chronic systemic inflammation caused by 
obesity are complex processes and involve many players [16]. The disturbances within WAT microenvironment occur at the immune and metabolic levels in obesity and obesityrelated conditions. Among these changes, increased levels of circulating free fatty acids (FFA) contribute to the development of insulin resistance [18]. Elevated levels of FFAs lead to the generation of new metabolites from FFA reesterification, such as diacylglycerol (DAG) [19]. DAG promotes the activation of several serine/threonine kinases, such as protein kinase C (PKC), which drastically impairs the phosphorylation of insulin receptor substrates (IRS) $1 / 2$, thereby disrupting insulin signaling [18-20].

Another important players in the induction and control of AT inflammation are the Toll-like receptors (TLR), in particular, TLR4 [21, 22]. TLR activation leads to defective cellular function in all metabolically relevant organs, such as the liver, pancreas, and WAT [20-24]. This defect in cellular function results in immune cell activation and inflammation subsequently leading to resistance to key metabolic hormones such as insulin, leptin, and ghrelin [23-27].

Ghrelin is a peptide-hormone/cytokine widely distributed throughout the gastric mucosa made up of 28 amino acids and is mainly secreted by X/A-like enteroendocrine cells [28-31]. Ghrelin was described in 1999 as an endogenous ligand for the growth hormone secretagogue receptor (GHS-R) [32], a G-coupled receptor broadly expressed in the central nervous system (CNS) and in peripheral tissues, including nerve cells, cardiac cells, adipocytes, and immune cells [32-34].

Ghrelin has an important role in obesity and metabolicrelated disorders. It is most known for its role in appetite regulation, acting directly on hypothalamic neurons responsible that were involved in feeding behavior [35]. Beyond this "classic" function, ghrelin is also an immunomodulatory hormone, providing new perspectives for its relevance in metabolic diseases [36, 37]. In obesogenic conditions, ghrelin levels are reduced with a concomitant induction of chronic low-grade inflammation $[23,38]$. These data strongly suggest a role for ghrelin in obesity-related pathological conditions in establishing and maintaining "metabolic inflammation" and expand our knowledge of ghrelin beyond its role in the CNS. In this review, we will discuss the participation of ghrelin in immunomodulatory events, the impact of this regulation on metabolic disorders, and the mechanisms by which ghrelin acts.

\section{Ghrelin Structure, Function, and Receptor}

The GHS-R has two isoforms, GHS-R1a and GHS-R1b [39]. Only GHS-R1a triggers a signaling pathway, which is induced by the binding of ghrelin [39]. The lack of GHS-R1b isoform activity is attributed to the absence of a third intracellular loop, which prevents $G$ protein coupling $[39,40]$. There is evidence describing the interaction between ghrelin receptor and other G-coupled receptors, such as dopamine, serotonin and melanocortin receptors, and even GHS-R1b [39, 41]. These interactions lead to conformational changes in GHS-R, which impact GHS-R1a signaling [39-41].
Secreted ghrelin is found in two distinct forms in the bloodstream [42]. One is the desacyl (desoctanoyl) form (desacyl-ghrelin), which is more stable and has higher serum concentration levels compared to other ghrelin form [43-45]. Desacyl-ghrelin is suggested to be a non-GHS-R1a ligand form of ghrelin under physiological conditions [31, 43, 45]. Desacyl-ghrelin has cardioprotective effects [46-48]. However, its functional role and the receptor by which desacylghrelin binds remain unknown $[39,49]$. The other form of ghrelin is the acylated form (acyl-ghrelin), which undergoes a posttranslational modification on serine residue 3 [50]. This acylated form corresponds to approximately $20 \%$ of total circulating ghrelin and is responsible for the biological effects of ghrelin [51] and indicates that acylation of ghrelin is an important step for the biological activity of this peptide [51-53].

The posttranslational structural modification observed in the acylated form of ghrelin is attributed to an enzyme, discovered in 2008 by Yang and colleagues [54], which is called ghrelin-O-acyltransferase (GOAT). GOAT is responsible for the acylation of the preproghrelin before it is transported to the Golgi apparatus [42]. In the Golgi vesicle, proghrelin is proteolytically cleaved by the prohormone convertase $1 / 3$ (PC 1/3) [31, 55, 56].

Acyl-ghrelin has a wide range of functions in several tissues. Acyl-ghrelin stimulates growth hormone secretion by the pituitary gland and activates the hypothalamic orexigenic axis [57]. Ghrelin serum levels are increased during caloric restriction [30]. In the hypothalamic orexigenic axis, ghrelin induces the secretion of neuropeptides, such as AgRP (agouti-related protein) and NPY (neuropeptide Y) [58], which leads to increased food consumption and reduced energy expenditure [53].

In addition to the direct effects of ghrelin on the CNS, ghrelin regulates gastrointestinal motility $[59,60]$, energy homeostasis [61], and the cardiovascular and reproductive systems [62]. Ghrelin also participates in the regulation of other adipokines, such as leptin, and modulates a broad number of immune functions [31,63].

\section{Ghrelin Signaling}

GHS-R1a is widely distributed in different tissues [32-34], and its activation by acyl-ghrelin involves several signaling pathways [28-30]. The most studied cell type regarding the mechanisms of actions of acyl-ghrelin is hypothalamic neurons $[64,65]$. In these cells, acyl-ghrelin relies on $5^{\prime}$ adenosine monophosphate-activated protein kinase (AMPK) [66-68]. Acyl-ghrelin AMPK-dependent signaling acts by two distinct mechanisms in hypothalamic neurons, in which intracellular calcium influx [69] and cytoplasmic nutrient sensors, such as AMPK [70] and mammalian target of rapamycin (mTOR), are the main targets triggered by the binding of acyl-ghrelin to GHS-R1a [71, 72].

AMPK activation leads to an inhibition of acetyl-CoA carboxylase (ACC) through posttranslational modifications [66]. The cellular outcome of this inhibition is increased mitochondrial metabolism due to consecutive activation of carnitine palmitoyltransferase 1 (CPT1) $[73,74]$. Increased 
fatty acid oxidation leads to the generation of reactive oxygen species (ROS) and consequently stimulates uncoupling protein 2 (UCP2) [75]. These events induce the expression of orexigenic neuropeptides and consequently feeding behavior [75]. AMPK activation through GHS-R1a can also be mediated by calcium calmodulin-dependent protein kinasekinase 2 (CAMKK2) in response to elevated intracellular calcium concentrations [76-78]. There is also evidence for a dependency on Sirtuin 1 and p53 during AMPK activation through GHS-R1a signaling [79].

The cytoplasmic nutrient sensor mTOR has a key function in hypothalamic energy homeostasis [80]. Several reports indicate that the effects of acyl-ghrelin are mediated by mTOR signaling pathway activation $[72,81,82]$. Activation of this machinery is responsible for the phosphorylation of several transcriptional factors, which are key elements in the orexigenic response, such as forkhead box protein $\mathrm{O} 1$ (FOXO-1) and cAMP response element-binding protein (CREB) [71, 83]. These data indicate that acyl-ghrelin signaling pathway in hypothalamic neurons is dependent on the signaling machinery of nutrient sensing.

In immune cells, the mechanisms of acyl-ghrelin signaling are poorly explored. Avallone and colleagues [84] show that ghrelin signaling in macrophages is dependent on AMPK activation and peroxisome proliferator-activated receptor gamma (PPAR $\gamma$ ) [84]. Both proteins have established anti-inflammatory roles [81-86]. Further studies are required to fully characterize acyl-ghrelin signaling in immune cells. The dependence of AMPK and PPAR $\gamma$ for the immunoregulatory features of acyl-ghrelin is consistent with the current understanding of ghrelin signaling events in hypothalamic neurons as well as the cellular modifications that immune cells undergo during the induction of an antiinflammatory phenotype [85-87].

3.1. Mechanisms Independent of Nutrient Sensors. There are two physiological outcomes as resultant of ghrelin receptor activation that does not depend on the nutrient sensing machinery: (i) the activation of hypothalamic neurons that evoke feeding behavior [69] and (ii) growth hormone $(\mathrm{GH})$ secretion by pituitary cells [88]. Both outcomes are a direct result of elevated calcium levels, with distinct mechanisms of action. In the first case, activation of GHS-R1a leads to a subsequent elevation of cyclic adenosine monophosphate (cAMP), mediated by the adenilate cyclase (AC)-protein kinase A (PKA) signaling pathway [89]. As a result, hypothalamic neurons involved in feeding behavior are activated [69]. In pituitary cells, activated GHS-R1a induces calcium release from endoplasmic reticulum, which results in the activation of phospholipase $\mathrm{C}$ (PLC)-inositol triphosphate $\left(\mathrm{IP}_{3}\right)$-protein kinase $\mathrm{C}$ (PKC) pathway $[39,88]$.

\section{Ghrelin, Obesity, and Inflammation}

Tissue-secreted factors may disturb tissue homeostasis, which affects cellular and tissue metabolism and leads to systemic alterations [26]. Ghrelin and other factors regulate several aspects of metabolism and inflammation, which result in improved or worsened insulin resistance and metabolic syndrome [90-92]. Obesity-mediated metabolic disturbances increase levels of several cytokines and chemokines $[91,93]$. This generates a proinflammatory status, which is a potential risk factor for the development of inflammationinduced insulin resistance [94]. One of these secreted factors is the monocyte chemotactic protein-1 (MCP-1), which is induced by the $\mathrm{NF} \kappa \mathrm{B}$ pathway to recruit monocytes [95]. Because activation of GHS-R reduces $\mathrm{NF} \kappa \mathrm{B}$ activation in endothelial cells [96], ghrelin treatment could limit immune cell activation through inhibition of $\mathrm{NF} \kappa \mathrm{B}$ activation and subsequent MCP-1 secretion. This approach may lead to the development of new therapeutic approaches to treat T2D.

Metabolic imbalance induced by obesity leads to alterations in ATM population profile [97]. The M1 ATM macrophage population expresses the cell surface marker $\mathrm{CD} 11 \mathrm{c}$ and secretes proinflammatory cytokines, such as tumor necrosis factor- $\alpha$ (TNF- $\alpha$ ), interleukin- $1 \beta$ (IL- $1 \beta$ ), interleukin-6 (IL-6), and monocyte chemotactic protein-1 (MCP-1) [98]. M1 macrophages also express high levels of iNOS (inducible nitric oxide synthase) [98, 99]. M2 macrophages express cell surface markers CD206, CD301, and CD163, secrete anti-inflammatory cytokines, such as interleukin-10 (IL-10), and express high levels of arginase-1 $[15,99]$. M2 ATMs are often involved in homeostasis maintenance and tissue repair $[15,100]$. The increase in the number of M1 ATM population in obesity is commonly accompanied with a reduction in M2 ATM population. This imbalance, with the predominance of a proinflammatory profile, inhibits the insulin-signaling pathway $[94,101,102]$. Thus, ATM function has an important role on metabolic syndrome and T2D development, which is frequently observed during obesity [99].

In obesogenic conditions, ghrelin levels are decreased [23] and levels of proinflammatory cytokines and adipokines, such as leptin, and liver-derived proteins, such as retinol binding 4 (RBP4), are increased [5, 103, 104]. Leptin is a proinflammatory adipokine, which inhibits ghrelin secretion [105] and worsens adipose tissue inflammation [5]. These data support the hypothesis that counter regulatory functions between leptin and ghrelin are an essential step for the maintenance of homeostasis CNS (food intake and energy expenditure regulation) and in immune responses [36].

\section{Immunoregulatory Functions of Ghrelin}

The wide distribution of functional ghrelin receptors (GHS-R) and their expression in various immune cell populations have attracted the attention of the scientific community. Changes in ghrelin levels can directly affect immune responses and tissue homeostasis [36, 37]. Leukocytes, such as adipose tissue macrophages (ATMs), express GHS-R [106] and detect changes in energy status [107, 108]. Thus, ghrelin actions on ATMs may play a role in the maintenance of the tissue homeostasis, suggesting a link between the immune system and systemic metabolism in response to different physiological and pathological conditions such as obesity and insulin resistance $[109,110]$. 

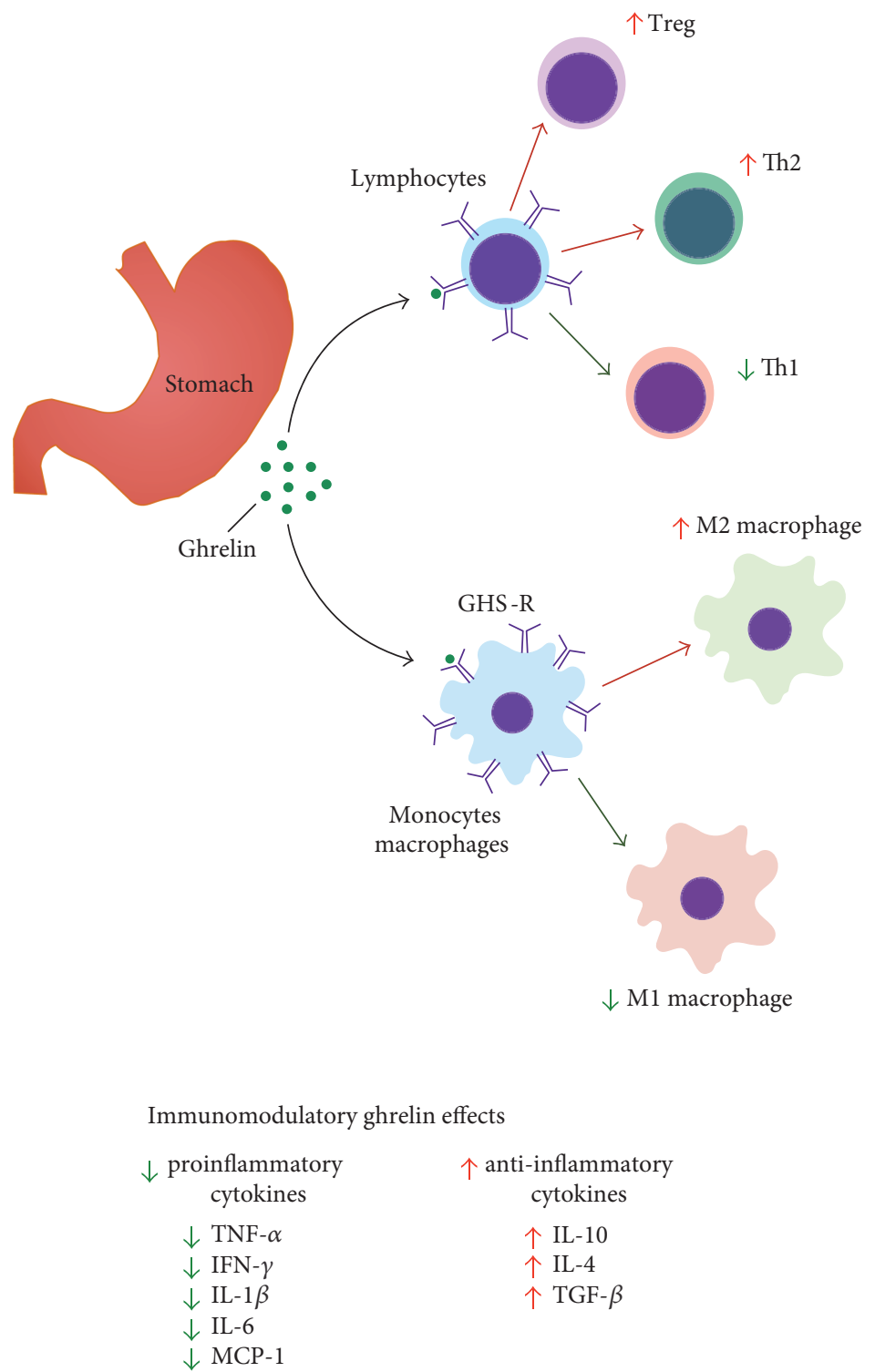

FIGURE 1: The immune roles of ghrelin. Ghrelin is secreted by X/A-like enteroendocrine cells. In the innate immune system, ghrelin acts on macrophages and induces an anti-inflammatory state (M2 profile) and inhibits proinflammatory macrophages (M1 profile). In the adaptive immune system, ghrelin exhibits an anti-inflammatory role. Ghrelin inhibits Th1 cells and increases the polarization of Th2 and regulatory $\mathrm{T}$ cells. These actions contribute to the reduced levels of proinflammatory cytokines and increased levels of antiinflammatory cytokines.

Several studies support an immunoregulatory role for ghrelin $[36,37,107,111,112]$. Ghrelin acts on a diverse portfolio of leukocytes and directly alters immune cell function (Figure 1) [36, 37, 111, 112]. Dixit and colleagues [111] showed that ghrelin treatment in vitro inhibited the secretion of proinflammatory cytokines (IL- $1 \beta$, IL- 6 , and TNF- $\alpha$ ) in human monocytes, $\mathrm{T}$ cells, and peripheral blood mononuclear cells (PBMCs) [111]. Likewise, ghrelin treatment in human umbilical vein endothelial cells (HUVEC) reduced the secretion of IL- 8 and MCP- 1 and the activation of $\mathrm{NF} \kappa \mathrm{B}$ in response to TNF- $\alpha$ stimuli [96]. Also, rats submitted to endotoxic shock with lipopolysaccharide (LPS) and treated with ghrelin had higher rates of survival compared to controls [113]. This protective effect was mediated by ghrelin-specific
GHS-R receptor binding and resulted in reduced serum levels of TNF- $\alpha$, IL- 6 , IL-8, and MCP-1 $[96,111]$. Moreover, data suggests that mitogen-activated protein kinase phosphatase1 (MKP-1) mediates the protective effect of ghrelin against endotoxic shock [114]. MKP-1 levels are reduced in inflammatory conditions, such as norepinephrine-induced sepsis, and lead to secretion of TNF- $\alpha$ [114]. Jacob and colleagues [114] reported that ghrelin treatment in septic rats increased gene and protein expression of MKP-1 [114]. This restoration of MKP-1 expression may partially explain the reduction in proinflammatory cytokines in response to ghrelin treatment. These data indicate that ghrelin can limit inflammation and plays an important role in metabolic and nonmetabolic inflammatory conditions. 
In vivo, ghrelin has an anti-inflammatory and antinociceptive role $[13,34,37,111,115-118]$. Intraperitoneal administration of ghrelin in rats submitted to pain resulted in increased levels of serum IL-10 and TGF- $\beta$ and reduced pain score [118]. The anti-inflammatory action of ghrelin was also observed in a colitis model. Ghrelin treatment reduced the expression of TNF- $\alpha$, INF- $\gamma$, IL- $1 \alpha$, IL- $1 \beta$, IL-6, IL-12, IL-15, IL-17, and IL-18 and increased IL-10 levels in colonic mucosa, which improved colitis score and survival rate in mice [37].

The anti-inflammatory roles of ghrelin can be extended to other inflammatory conditions, such as rheumatoid arthritis. Administration of the ghrelin agonist growth hormone-releasing peptide-2 (GHRP-2) reduced serum IL-6 levels and improved inflammation in arthritic rats [119]. Similar observations were obtained when peritoneal macrophages were treated with GHRP-2 in vitro [119]. Together, this data indicates that GHS-R can be used as a novel target for the treatment of acute and chronic inflammatory diseases.

Neutrophils play a fundamental role in immune response against pathogens and are regulated by ghrelin treatment. In vivo studies show that ghrelin treatment reduced neutrophil count in peritoneal lavage [63]. This was not attributed to enhanced apoptosis [120]. Neutrophils treated with ghrelin had increased phagocytic capacity and enhanced bactericidal capacity [120]. On the other hand, ghrelin treatment reduced neutrophil recruitment in the airways of subjects with chronic respiratory infections, which displayed reduced IL8 and TNF- $\alpha$ levels in the sputum and improved overall inflammatory status [121].

Orlova and colleagues showed that ghrelin may affect dendritic cell- (DC-) mediated antigen presentation capacity. DCs treated with ghrelin had reduced capacity to induce the secretion of IL-17 and INF- $\gamma$ and enhanced capacity to induce secretion of IL-10 and TGF- $\beta$ from cocultured T cells [122]. Ghrelin also modulates thymic DCs. Ghrelin administration in the thymus induced the proliferation of DCs in aged mice [123], which contributes to a more effective maturation and response of effector and regulatory (Treg) $\mathrm{T}$ cell differentiation [124]. Ghrelin also regulates immune cell migration and proliferation. Ghrelin treatment reduced immune cell recruitment after LPS stimulation and induced the proliferation of Treg cells $[34,125]$. Together, these data indicate that ghrelin has important effects in modulating $\mathrm{T}$ cells, especially regulatory $\mathrm{T}$ cells.

The role of adaptive immunity in the CNS is a growing topic of study. One of the most established models of the role of lymphocytes in CNS homeostasis is experimental autoimmune encephalomyelitis (EAE), an animal model of multiple sclerosis [126]. This condition has a marked proinflammatory feature, mediated by $\mathrm{T} \mathrm{CD} 4^{+}$cells (Th1 and/or Th17 response) [125]. Ghrelin exerts therapeutic effects in EAE through the impairment of encephalitogenic Th1 and Th17 cells, and short-term ghrelin treatment reduces the clinical score of the disease [125]. This was associated with fewer infiltrated cells in the CNS and subsequent reduction in CNS inflammation. These effects were further improved by the induction of regulatory $\mathrm{T}$ cells in mice [125]. SouzaMoreira and colleagues [125] showed that ghrelin treatment suppressed M1 phenotype in microglia and reduced $\mathrm{T}$ cell infiltration, which was consistent with findings previously described by Theil and colleagues [125, 127]. The immunomodulatory roles of ghrelin in CNS are a result of decreased expression of proinflammatory cytokines, such as TNF- $\alpha$, IL- $1 \beta$, and IL-6, which indicate a noteworthy antiinflammatory property.

\section{Contrasting Roles of Ghrelin in the Immune System}

There is evidence supporting the immunoregulatory role of acyl-ghrelin [107] and its beneficial effects to treat chronic inflammatory syndromes, especially acyl-ghrelin immunoprotective properties during endotoxic shock [36]. However, in sepsis, ghrelin may contribute to the higher mortality seen in septic mice [63]. This higher mortality was attributed to reduced neutrophil and natural killer cell activity, which led to increased bacterial burden [63]. Nevertheless, other authors demonstrated beneficial effects of acyl-ghrelin in the same experimental model and attributed these effects to lower inflammation in the hippocampus, observed by the reduction of TNF- $\alpha$ and IL-6 levels in septic brains [112].

Desacyl-ghrelin is a non-GHS-R1a ligand and was previously described as the nonactive form of ghrelin (although some authors report that desacyl-ghrelin binds to GHS-Rla when supraphysiological concentrations are induced) $[34,39,44,128]$. Recent reports suggest that desacyl-ghrelin alters macrophage polarization in vitro [129]. Desacyl-ghrelin treatment decreased expression of TNF- $\alpha$ and CD11c and increased expression of CD206 in the mouse macrophage cell line (RAW264.7) [129]. Similar results were observed by the treatment of RAW cells with acyl-ghrelin [130]. This suggests that ghrelin treatment reduced M1 proinflammatory macrophage and increased M2 macrophage polarization [129]. These results are compatible with the observation that in humans, monocytes are the main targets for the anti-inflammatory actions of acyl-ghrelin [111]. However, the effects of acyl-ghrelin or desacyl-ghrelin treatment in bone marrow-derived macrophages or ATMs remain to be established.

Knockdown of GHS-R in mice reduced expression of TNF- $\alpha$, IL- $1 \beta$, IL- 6 , and MCP- 1 in WAT of mice fed with a high-fructose corn syrup, which was associated with improved insulin sensitivity and obesity in aged mice. Also, ablation of the GHS-R promoted a shift towards a M2 profile in ATMs [106]. GHS-R ablation also limited the proinflammatory phenotype of peritoneal macrophages and ATMs, which was observed by decreased expression of proinflammatory cytokines [99].

Although a variety of studies indicates that ghrelin has an anti-inflammatory role, the controversial actions of this peptide support the need to better understand the mechanisms by which ghrelin acts on immune cells in response to different immunological challenges. 


\section{Ghrelin at the Neuroimmune Interface}

7.1. Neuroprotective Effects of Ghrelin. In extrahypothalamic areas, acyl-ghrelin has a strong anti-inflammatory role [131-134]. Microglial cells express GHS-R, and acyl-ghrelin administration downregulates proinflammatory cytokine expression through impairment of microglial cell expansion [131-133]. The neuroprotective effects of acyl-ghrelin were extensively studied by many research groups [135-137]. In Parkinson's disease, there is a progressive neuronal degeneration of dopaminergic neurons localized in the substantia nigra and a concomitant increase in microglial activation. GHS-R1a is widely expressed in dopaminergic neurons in the substantia nigra $[136,137]$. It is proposed that the neuroprotective effects of acyl-ghrelin in a Parkinson's disease context are partially due to the induction of tyrosine hydroxylase expression in dopaminergic neurons, a pivotal enzyme in dopamine biosynthesis [135]. The administration of MPTP (1-methyl-4-phenyl-1,2,3,6-tetrahydropyridine), a mitochondrial toxin, is a well-established model for Parkinson's disease studies, since there is a selective effect on dopaminergic neurons [138]. Mice treated with intraperitoneal acyl-ghrelin have lower levels of neuronal death and reduced dopamine loss $[132,133,135]$. Consistent with this phenotype, ghrelin treatment reduces proinflammatory markers, such as TNF- $\alpha$ and IL- $1 \beta$ [133]. It is proposed that the neuroprotective effects of ghrelin are also mediated through UCP2 activity [75, 135], since striatal neurons are dependent on UCP2 for optimal function [139-142].

Learning and memory retention also are influenced by acyl-ghrelin [143]. Intracerebroventricular [144] and intrahippocampal [145] acyl-ghrelin injections improve memory retention in rodents, which suggests a role for ghrelin in the molecular process of memory acquisition and/or consolidation. These results are reinforced by data published by Diano and colleagues [146], where spine density in the hippocampus is reduced in ghrelin knockout mice [146]. Data from Carlini and colleagues [144, 147] suggest that these beneficial effects are partially due to serotonergic inputs from dorsal raphe nucleus to the hippocampal circuits [147].

Several studies indicate that the brain is not a postmitotic structure in adult life [148-151]. Adult neurogenesis may be a potential therapeutic target for many neurodegenerative conditions [152-154]. The most explored structure in this context is the hippocampus [155]. There is evidence that acyl-ghrelin induces neurogenesis in brain structures related with cognition, such as the dendate gyrus of the hippocampus [156]. The classical target of ghrelin resides in the neuronal populations of the hypothalamus, and there are no reports to date describing the induction of neurogenesis by ghrelin. Therefore, neuroprotective effects of ghrelin in cognition-related structures may contribute to both the regulation of neurogenic events and the maintenance of mature resident cells [157-159].

The neuroprotective effects of ghrelin are also related to ischemic lesions, both in vivo and in vitro [160-162]. In these situations, there is insufficient blood flow into the brain. Treatment with acyl-ghrelin reduces ischemic lesions in mice by mechanisms both dependent and independent of GHSRla [160-162]. Here, neuroprotection is determined as reduced infarct tissue and cell death $[161,163]$.

7.2. Ghrelin, Stress, and Neuroinflammation. In view with the increased incidence of psychological disturbances and obesity, many groups have investigated the dynamic contribution of obesity to the development of affective disorders and how affective disorders affect obesity. Hormones that regulate energy homeostasis, such as ghrelin, may play a role in mediating psychological disturbances [164].

Serum levels of acyl- and desacyl-ghrelin, preproghrelin, and $\mathrm{GH}$ are increased in rodents submitted to acute and chronic stress models [164-168]. The hypothesis that increased ghrelin levels could be due to a stress response is supported by the involvement of ghrelin in neuroprotection, memory, and motivation [143]. GHS-R knockout mice have depressive behavior, which is marked by social isolation [165]. Cummings and colleagues showed that the increased ghrelin levels lead to decreased depressive behavior in rodents submitted to forced swimming test [165]. Psychological stress appears to induce inflammatory responses and is associated with compartmental alterations characterized by depressive symptoms [169]. Elevated levels of proinflammatory cytokines are found in patients with depression [170]. IL- $1 \beta$ and TNF- $\alpha$ increase serotonin uptake and metabolism, which contribute to depressive behavior. These data suggest a link between inflammatory responses and compartmental diseases [170]. GHS-R expression in the basolateral complex of the amygdala, an important region for emotional processing in rodents and humans, strongly supports the involvement of ghrelin in the modulation of emotional status and memory [171, 172]. Thus, ghrelin treatment could be an effective approach against emotional disorders due to ghrelin anti-inflammatory properties [143, 170].

Alterations in endogenous ghrelin levels and action could lead to the development of psychiatric disturbances associated to stress [172, 173]; a better understanding of how ghrelin regulates emotional behavioral disturbances is needed. These studies may contribute to the development of new targets for the treatment of diseases associated with stress and inflammation.

7.3. Ghrelin and Mediobasal Hypothalamus. The hypothalamus is a CNS structure primarily involved in global metabolic regulation [35]. There are multiple hypothalamic nuclei involved with metabolic regulation, such as the arcuate nucleus (Arc), lateral hypothalamic area (LHA), and paraventricular nucleus (PVN) [35]. The current model stipulates that Arc neuronal populations work in a binary-like system. The anorexigenic response is mediated by proopiomelanocortin (POMC) neurons, and the orexigenic response is mediated by agouti-related protein (AgRP) expressing neurons [35]. The signals induced by key metabolic hormones and nutrients are perpetuated by other neuronal populations in different hypothalamic nuclei that are synaptically connected to AgRP/POMC neurons [35]. Ghrelin exerts its orexigenic actions through AgRP neurons exclusively, since POMC neurons do not express GSH-R [174]. 


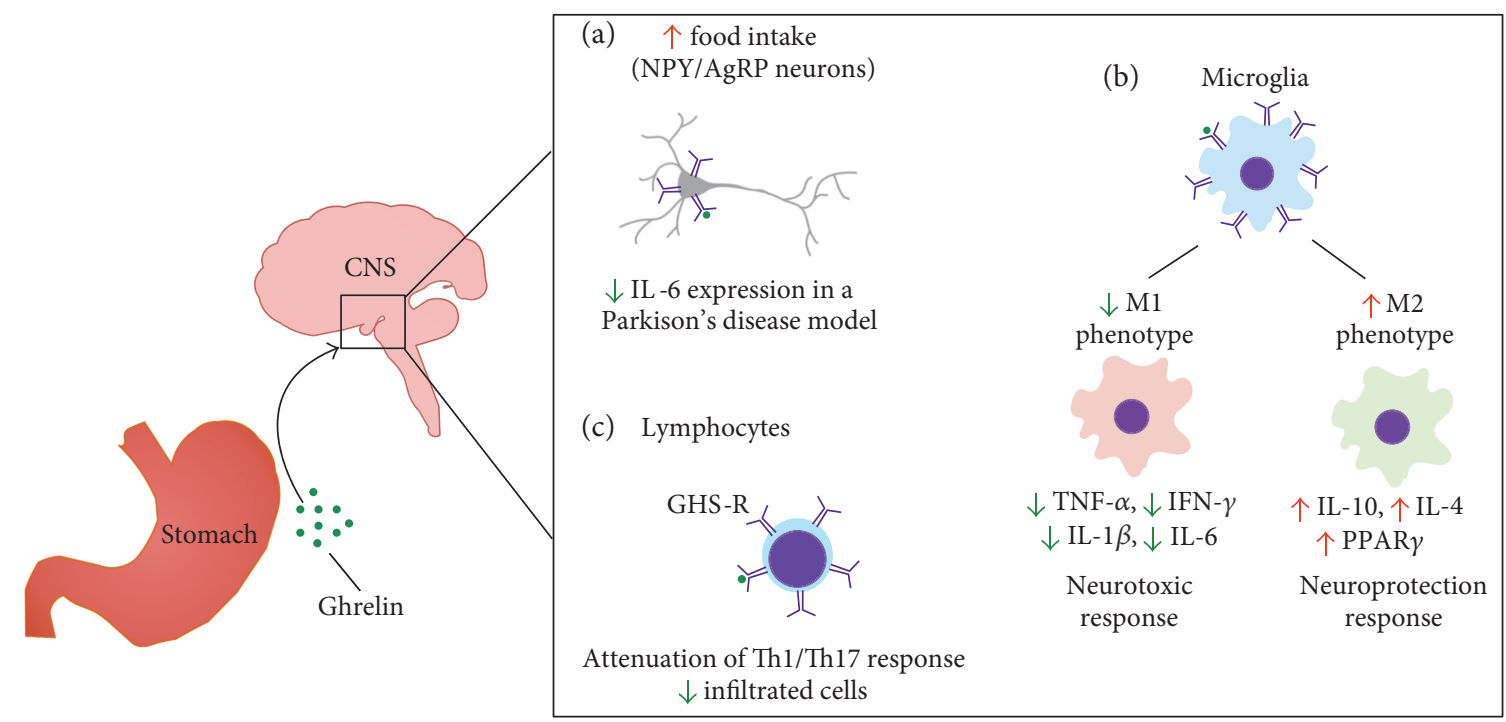

FIGURE 2: Ghrelin at the neuroimmune interface. Ghrelin has several functions in the CNS. (a) The classical orexigenic effect of ghrelin is mediated through activation of AgRP/NPY neurons in the mediobasal hypothalamus; it can also exert neuroprotective effects by diminishing IL-6 expression in striatal neurons in a Parkinson's disease model. (b) In microglia, ghrelin suppresses the proinflammatory phenotype and activates an anti-inflammatory program, which reinforces the neuroprotective role of ghrelin. (c) Infiltrated lymphoid cells are also decreased upon ghrelin treatment, with a marked reduction in Th1/Th17 responses.

It is known that consumption of high-fat diet (HFD) leads to activation of proinflammatory processes in the hypothalamus with marked deregulation of feeding behavior and defective energy expenditure responses [175-177]. This inflammatory process is activated in the early stages of HFD feeding, with increased cytokine expression within 24 hours after HFD intake [176]. The key cell type that coordinates inflammatory responses in CNS is the microglia [178]. Several reports in the past decade described the importance of microglial cells in the initiation and perpetuation of hypothalamic inflammation and consequently its repercussions [175-177]. Following an obesogenic stimulus, microglial cells are activated in a TLR4-dependent manner and rapidly expand, creating a proinflammatory environment. These actions are restricted to the hypothalamus in the early stages of "metabolic inflammation" [175]. A recent report demonstrated that inhibition of microglial expansion in the Arc partially restored the metabolic impairments due to an obesogenic environment [177]. Thus, microglial activation is one of the most important targets for the development of focusing on the CNS under obese conditions.

The activation of TLR4-dependent responses in resident Arc microglial cells leads to a defective ghrelin orexigenic effect in animals fed with a chow diet [179]. This data indicates that microglia can directly modulate energy homeostasis by affecting neighboring cell functions and might explain the counterintuitive phenomenon of ghrelin resistance in obesity and metabolic diseases. However, ghrelin resistance is a complex subject of study and cannot be reduced to isolated effects on microglial or neuronal cells in the hypothalamus [180]. For instance, it is not known whether ghrelin resistance is due to (i) reduced ghrelin receptor expression/ translocation in the target cells, (ii) defective ghrelin transport through blood-brain barrier as observed with leptin
[181], or (iii) disrupted cellular homeostasis on ghrelin responsive cells, which is a similar process that leptin responsive cells undergo in obesogenic conditions [181, 182]. It is also possible that the physiological outcome is a combination of all of these factors. Another point to be clarified is whether neurons and glial cells are both resistant to the ghrelin signal and if there is temporal concordance in the establishment of ghrelin resistance in different cell types.

7.4. Obesity and Immunity in the Central Nervous System. The participation of Th1 or Th17 cells on hypothalamic impairment in metabolic diseases has yet to be clarified. It is known that $\mathrm{T}$ cells can penetrate the blood-brain barrier and act locally on the brain [183]. Thus far, there is no characterization of the participation of these cell types in the induction of metabolic inflammation on the hypothalamus. It is possible that ghrelin exerts an indirect immunomodulatory effect on adaptive immunity. As briefly discussed, Arc microglial activation can lead to an increase in local TNF [176]. This signaling has multiple effects and is one modulator of adaptive immunity in the periphery, which triggers adipose tissue lipolysis and raises triglyceride levels in the blood [184]. This in turn elevates the number of B cells and $\mathrm{T}$ cells with a Th1-type profile [184]. Thus, in obesity and obesity-related conditions, the immunomodulatory mechanisms of ghrelin have multiple points of actions and might not be restricted to the neural tissue (Figure 2).

Long-term studies indicate that bariatric surgery promotes a significant and sustained weight loss and recovery of metabolic parameters [185]. Several works have reported alterations in ghrelin levels during the postoperative period in patients submitted to different surgical strategies, which could be a result of altered body weight and feeding behavior [165, 186-206]. 
Faraj and colleagues [199] reported that ghrelin levels are dynamically modulated with weight loss [199] and patients with no changes in body weight do not have altered ghrelin levels. However, the role of ghrelin in postbariatric surgery is controversial [165, 186-206]. Besides, another relevant aspect that should be considered is the different methodological approaches used for the measurement of ghrelin, which could contribute to the discrepancy in ghrelin levels reported [207, 208].

Although the exact mechanisms by which bariatric surgery leads to reduced body weight are not completely understood, alterations in nutrient influx accompanied by increased ghrelin levels could lead to reduced proinflammatory marker expression, which will result in improved metabolic inflammation and the subsequent glucose homeostasis [199, 209-212].

\section{Concluding Remarks}

Ghrelin is not only a gastric peptide with CNS actions but it is also an important hormone/cytokine with important pleiotropic functions. The wide distribution of GHS-R1a in different cell types, including immune cells, indicates that ghrelin acts as a potent immunomodulator with powerful anti-inflammatory roles. The anti-inflammatory effects of ghrelin are observed in immune cells of both myeloid and lymphoid lineages. In macrophages/microglia, these antiinflammatory properties are translated into increased secretion of anti-inflammatory cytokines, elevated $\mathrm{M} 2 / \mathrm{M} 1$ ratio, and reduced proinflammatory cytokine expression. In lymphoid cells, ghrelin signaling leads to increased Th2 and Treg cell function. Therefore, ghrelin is a secreted hormone/cytokine with important anti-inflammatory roles in metabolically relevant organs, such as WAT and the hypothalamus. Ghrelin is a promising therapeutic strategy for the treatment of chronic inflammatory conditions, such as obesity. The therapeutic function of ghrelin is currently limited by its potent orexigenic properties. The paradoxical outcomes of ghrelin used to treat metabolic diseases are the induction of appetite and the anti-inflammatory roles. Thus, more studies are required to elucidate the molecular mechanisms of ghrelin actions as well as its application as a GHS-R agonist to treat obesity and insulin resistance in individuals.

\section{Conflicts of Interest}

The authors declare that there is no conflict of interests regarding the publication of this paper.

\section{Authors' Contributions}

Jéssica Aparecida da Silva Pereira and Felipe Corrêa da Silva contributed equally to this work.

\section{Acknowledgments}

The authors acknowledge the support of the State of São Paulo Foundation for Research Support (FAPESP, no. 2015/15626-8 and no. 2017/06225-5) and CNPq. The authors also thank Dr. Jennifer Lee from Beth Israel Deaconess Medical Center and Dr. Marisa Moura Momoli for revising the manuscript.

\section{References}

[1] WHO, "Obesity and overweight 2016," http://www.who.int/ mediacentre/factsheets/fs311/en/.

[2] J. Cawley, J. A. Rizzo, and K. Haas, "Occupation-specific absenteeism costs associated with obesity and morbid obesity," Journal of Occupational and Environmental Medicine, vol. 49, no. 12, pp. 1317-1324, 2007.

[3] D. M. Gates, P. Succop, B. J. Brehm, G. L. Gillespie, and B. D. Sommers, "Obesity and presenteeism: the impact of body mass index on workplace productivity," Journal of Occupational and Environmental Medicine, vol. 50, no. 1, pp. 39-45, 2008.

[4] N. A. Fairbridge, T. M. Southall, D. C. Ayre et al., "Loss of CD24 in mice leads to metabolic dysfunctions and a reduction in white adipocyte tissue," PLoS One, vol. 10, no. 11, article e0141966, 2015.

[5] V. Andrade-Oliveira, N. O. Camara, and P. M. MoraesVieira, "Adipokines as drug targets in diabetes and underlying disturbances," Journal of Diabetes Research, vol. 2015, Article ID 681612, 11 pages, 2015.

[6] P. M. Moraes-Vieira, E. J. Bassi, R. C. Araujo, and N. O. Câmara, "Leptin as a link between the immune system and kidney-related diseases: leading actor or just a coadjuvant?," Obesity Reviews, vol. 13, no. 8, pp. 733-743, 2012.

[7] M. Lafontan and M. Berlan, "Do regional differences in adipocyte biology provide new pathophysiological insights?," Trends in Pharmacological Sciences, vol. 24, no. 6, pp. 276283, 2003.

[8] B. Antuna-Puente, B. Feve, S. Fellahi, and J. P. Bastard, "Adipokines: the missing link between insulin resistance and obesity," Diabetes \& Metabolism, vol. 34, no. 1, pp. 211,2008

[9] M. Rosenbaum, M. Sy, K. Pavlovich, R. L. Leibel, and J. Hirsch, "Leptin reverses weight loss-induced changes in regional neural activity responses to visual food stimuli," The Journal of Clinical Investigation, vol. 118, no. 7, pp. 2583-2591, 2008.

[10] P. M. Moraes-Vieira, A. Saghatelian, and B. B. Kahn, "GLUT4 expression in adipocytes regulates de novo lipogenesis and levels of a novel class of lipids with antidiabetic and anti-inflammatory effects," Diabetes, vol. 65, no. 7, pp. 1808-1815, 2016.

[11] M. E. Vazquez-Vela, N. Torres, and A. R. Tovar, "White adipose tissue as endocrine organ and its role in obesity," Archives of Medical Research, vol. 39, no. 8, pp. 715-728, 2008.

[12] C. M. Oller do Nascimento, E. B. Ribeiro, and L. M. Oyama, "Metabolism and secretory function of white adipose tissue: effect of dietary fat," Anais da Academia Brasileira de Ciências, vol. 81, no. 3, pp. 453-466, 2009.

[13] S. Galic, J. S. Oakhill, and G. R. Steinberg, "Adipose tissue as an endocrine organ," Molecular and Cellular Endocrinology, vol. 316, no. 2, pp. 129-139, 2010.

[14] N. S. Kalupahana, N. Moustaid-Moussa, and K. J. Claycombe, "Immunity as a link between obesity and insulin resistance," Molecular Aspects of Medicine, vol. 33, no. 1, pp. 26-34, 2012. 
[15] A. Castoldi, C. Naffah de Souza, N. O. Câmara, and P. M. Moraes-Vieira, "The macrophage switch in obesity development," Frontiers in Immunology, vol. 6, p. 637, 2015.

[16] S. Sun, Y. Ji, S. Kersten, and L. Qi, "Mechanisms of inflammatory responses in obese adipose tissue," Annual Review of Nutrition, vol. 32, pp. 261-286, 2012.

[17] J. C. McNelis and J. M. Olefsky, "Macrophages, immunity, and metabolic disease," Immunity, vol. 41, no. 1, pp. 36-48, 2014.

[18] G. Boden, "Obesity and free fatty acids," Endocrinology and Metabolism Clinics of North America, vol. 37, no. 3, pp. 635-646, 2008, viii-ix.

[19] G. Boden, "Obesity, insulin resistance and free fatty acids," Current Opinion in Endocrinology, Diabetes, and Obesity, vol. 18, no. 2, pp. 139-143, 2011.

[20] C. Yu, Y. Chen, G. W. Cline et al., "Mechanism by which fatty acids inhibit insulin activation of insulin receptor substrate-1 (IRS-1)-associated phosphatidylinositol 3-kinase activity in muscle," The Journal of Biological Chemistry, vol. 277, no. 52, pp. 50230-50236, 2002.

[21] H. Shi, M. V. Kokoeva, K. Inouye, I. Tzameli, H. Yin, and J. S. Flier, "TLR4 links innate immunity and fatty acid-induced insulin resistance," The Journal of Clinical Investigation, vol. 116, no. 11, pp. 3015-3025, 2006.

[22] A. C. Konner and J. C. Bruning, "Toll-like receptors: linking inflammation to metabolism," Trends in Endocrinology and Metabolism, vol. 22, no. 1, pp. 16-23, 2011.

[23] M. Tschop, C. Weyer, P. A. Tataranni, V. Devanarayan, E. Ravussin, and M. L. Heiman, "Circulating ghrelin levels are decreased in human obesity," Diabetes, vol. 50, no. 4, pp. 707-709, 2001.

[24] A. L. Mark, M. L. Correia, K. Rahmouni, and W. G. Haynes, "Selective leptin resistance: a new concept in leptin physiology with cardiovascular implications," Journal of Hypertension, vol. 20, no. 7, pp. 1245-1250, 2002.

[25] M. J. Song, K. H. Kim, J. M. Yoon, and J. B. Kim, “Activation of Toll-like receptor 4 is associated with insulin resistance in adipocytes," Biochemical and Biophysical Research Communications, vol. 346, no. 3, pp. 739-745, 2006.

[26] C. J. Andersen, K. E. Murphy, and M. L. Fernandez, "Impact of obesity and metabolic syndrome on immunity," Advances in Nutrition, vol. 7, no. 1, pp. 66-75, 2016.

[27] P. M. Moraes-Vieira, E. J. Bassi, R. A. Larocca et al., "Leptin deficiency modulates allograft survival by favoring a Th2 and a regulatory immune profile. [corrected]," American Journal of Transplantation, vol. 13, no. 1, pp. 36-44, 2013.

[28] M. L. Barreiro, F. Gaytan, J. E. Caminos et al., "Cellular location and hormonal regulation of ghrelin expression in rat testis," Biology of Reproduction, vol. 67, no. 6, pp. 17681776,2002

[29] S. Gnanapavan, B. Kola, S. A. Bustin et al., "The tissue distribution of the mRNA of ghrelin and subtypes of its receptor, GHS-R, in humans," The Journal of Clinical Endocrinology and Metabolism, vol. 87, no. 6, p. 2988, 2002.

[30] C. De Vriese and C. Delporte, "Ghrelin: a new peptide regulating growth hormone release and food intake," The International Journal of Biochemistry \& Cell Biology, vol. 40, no. 8, pp. 1420-1424, 2008.

[31] A. Stengel and Y. Tache, "Ghrelin - a pleiotropic hormone secreted from endocrine x/a-like cells of the stomach," Frontiers in Neuroscience, vol. 6, p. 24, 2012.
[32] M. Kojima, H. Hosoda, Y. Date, M. Nakazato, H. Matsuo, and K. Kangawa, "Ghrelin is a growth-hormone-releasing acylated peptide from stomach," Nature, vol. 402, no. 6762, pp. 656-660, 1999.

[33] G. Wang, H. M. Lee, E. Englander, and G. H. Greeley Jr., "Ghrelin-not just another stomach hormone," Regulatory Peptides, vol. 105, no. 2, pp. 75-81, 2002.

[34] D. Baatar, K. Patel, and D. D. Taub, "The effects of ghrelin on inflammation and the immune system," Molecular and Cellular Endocrinology, vol. 340, no. 1, pp. 4458, 2011.

[35] M. W. Schwartz, S. C. Woods, D. Porte Jr., R. J. Seeley, and D. G. Baskin, "Central nervous system control of food intake," Nature, vol. 404, no. 6778, pp. 661-671, 2000.

[36] V. D. Dixit and D. D. Taub, "Ghrelin and immunity: a young player in an old field," Experimental Gerontology, vol. 40, no. 11, pp. 900-910, 2005.

[37] E. Gonzalez-Rey, A. Chorny, and M. Delgado, "Therapeutic action of ghrelin in a mouse model of colitis," Gastroenterology, vol. 130, no. 6, pp. 1707-1720, 2006.

[38] K. Takagi, R. Legrand, A. Asakawa et al., "Anti-ghrelin immunoglobulins modulate ghrelin stability and its orexigenic effect in obese mice and humans," Nature Communications, vol. 4, p. 2685, 2013.

[39] C. Delporte, "Structure and physiological actions of ghrelin," Scientifica (Cairo), vol. 2013, Article ID 518909, 25 pages, 2013.

[40] K. B. Chow, J. Sun, K. M. Chu, W. Tai Cheung, C. H. Cheng, and $\mathrm{H}$. Wise, "The truncated ghrelin receptor polypeptide (GHS-R1b) is localized in the endoplasmic reticulum where it forms heterodimers with ghrelin receptors (GHS-R1a) to attenuate their cell surface expression," Molecular and Cellular Endocrinology, vol. 348, no. 1, pp. 247-254, 2012.

[41] T. D. Muller, R. Nogueiras, M. L. Andermann et al., "Ghrelin," Molecular Metabolism, vol. 4, no. 6, pp. 437-460, 2015.

[42] Z. B. Andrews, "Central mechanisms involved in the orexigenic actions of ghrelin," Peptides, vol. 32, no. 11, pp. 22482255, 2011.

[43] M. Korbonits, A. P. Goldstone, M. Gueorguiev, and A. B. Grossman, "Ghrelin-a hormone with multiple functions," Frontiers in Neuroendocrinology, vol. 25, no. 1, pp. 27-68, 2004.

[44] M. Camilleri, A. Papathanasopoulos, and S. T. Odunsi, "Actions and therapeutic pathways of ghrelin for gastrointestinal disorders," Nature Reviews Gastroenterology \& Hepatology, vol. 6, no. 6, pp. 343-352, 2009.

[45] F. Mirzaie Bavil, G. Mohaddes, H. Ebrahimi, R. Keyhanmanesh, R. Ghiyasi, and M. R. Alipour, "Ghrelin increases lymphocytes in chronic normobaric hypoxia," Advanced Pharmaceutical Bulletin, vol. 4, no. 4, pp. 339343, 2014.

[46] G. Baldanzi, N. Filigheddu, S. Cutrupi et al., "Ghrelin and desacyl ghrelin inhibit cell death in cardiomyocytes and endothelial cells through ERK1/2 and PI 3-kinase/AKT," The Journal of Cell Biology, vol. 159, no. 6, pp. 1029-1037, 2002.

[47] L. Li, L. K. Zhang, Y. Z. Pang et al., "Cardioprotective effects of ghrelin and des-octanoyl ghrelin on myocardial injury induced by isoproterenol in rats," Acta Pharmacologica Sinica, vol. 27, no. 5, pp. 527-535, 2006. 
[48] G. Togliatto, A. Trombetta, P. Dentelli et al., "Unacylated ghrelin rescues endothelial progenitor cell function in individuals with type 2 diabetes," Diabetes, vol. 59, no. 4, pp. 1016-1025, 2010.

[49] D. E. Cummings, "Ghrelin and the short- and long-term regulation of appetite and body weight," Physiology \& Behavior, vol. 89, no. 1, pp. 71-84, 2006.

[50] K. Kirsz and D. A. Zieba, "Ghrelin-mediated appetite regulation in the central nervous system," Peptides, vol. 32, no. 11, pp. 2256-2264, 2011.

[51] T. R. Castaneda, J. Tong, R. Datta, M. Culler, and M. H. Tschöp, "Ghrelin in the regulation of body weight and metabolism," Frontiers in Neuroendocrinology, vol. 31, no. 1, pp. 44-60, 2010.

[52] M. Kojima, H. Hosoda, H. Matsuo, and K. Kangawa, "Ghrelin: discovery of the natural endogenous ligand for the growth hormone secretagogue receptor," Trends in Endocrinology and Metabolism, vol. 12, no. 3, pp. 118-122, 2001.

[53] T. Sato, Y. Nakamura, Y. Shiimura, H. Ohgusu, K. Kangawa, and M. Kojima, "Structure, regulation and function of ghrelin," Journal of Biochemistry, vol. 151, no. 2, pp. 119128, 2012.

[54] J. Yang, M. S. Brown, G. Liang, N. V. Grishin, and J. L. Goldstein, "Identification of the acyltransferase that octanoylates ghrelin, an appetite-stimulating peptide hormone," Cell, vol. 132, no. 3, pp. 387-396, 2008.

[55] O. Al Massadi, M. H. Tschop, and J. Tong, "Ghrelin acylation and metabolic control," Peptides, vol. 32, no. 11, pp. 23012308, 2011.

[56] L. K. Chopin, I. Seim, C. M. Walpole, and A. C. Herington, "The ghrelin axis-does it have an appetite for cancer progression?," Endocrine Reviews, vol. 33, no. 6, pp. 849-891, 2012.

[57] M. Kojima, "The discovery of ghrelin-a personal memory," Regulatory Peptides, vol. 145, no. 1-3, pp. 2-6, 2008.

[58] M. Kojima and K. Kangawa, "Ghrelin: structure and function,” Physiological Reviews, vol. 85, no. 2, pp. 495-522, 2005.

[59] Y. Masuda, T. Tanaka, N. Inomata et al., "Ghrelin stimulates gastric acid secretion and motility in rats," Biochemical and Biophysical Research Communications, vol. 276, no. 3, pp. 905-908, 2000.

[60] C. Dornonville de la Cour, E. Lindstrom, P. Norlén, and R. Håkanson, "Ghrelin stimulates gastric emptying but is without effect on acid secretion and gastric endocrine cells," Regulatory Peptides, vol. 120, no. 1-3, pp. 23-32, 2004.

[61] P. J. Delhanty and A. J. van der Lely, "Ghrelin and glucose homeostasis,” Peptides, vol. 32, no. 11, pp. 2309-2318, 2011.

[62] H. Ueno, H. Yamaguchi, K. Kangawa, and M. Nakazato, "Ghrelin: a gastric peptide that regulates food intake and energy homeostasis," Regulatory Peptides, vol. 126, no. 1-2, pp. 11-19, 2005.

[63] D. Siegl, E. F. Midura, T. Annecke, P. Conzen, C. C. Caldwell, and J. Tschoep, "The effect of ghrelin upon the early immune response in lean and obese mice during sepsis," PLoS One, vol. 10, no. 4, article e0122211, 2015.

[64] M. Tschop, D. L. Smiley, and M. L. Heiman, "Ghrelin induces adiposity in rodents," Nature, vol. 407, no. 6806, pp. 908-913, 2000.

[65] M. Nakazato, N. Murakami, Y. Date et al., "A role for ghrelin in the central regulation of feeding," Nature, vol. 409, no. 6817 , pp. 194-198, 2001.
[66] U. Andersson, K. Filipsson, C. R. Abbott et al., "AMPactivated protein kinase plays a role in the control of food intake," The Journal of Biological Chemistry, vol. 279, no. 13, pp. 12005-12008, 2004.

[67] D. G. Hardie, "AMPK: a key regulator of energy balance in the single cell and the whole organism," International Journal of Obesity, vol. 32, Supplement 4, pp. S7-S12, 2008.

[68] B. Kola, I. Farkas, M. Christ-Crain et al., "The orexigenic effect of ghrelin is mediated through central activation of the endogenous cannabinoid system," PLoS One, vol. 3, no. 3, article e1797, 2008.

[69] D. Kohno, H. Z. Gao, S. Muroya, S. Kikuyama, and T. Yada, "Ghrelin directly interacts with neuropeptide-Y-containing neurons in the rat arcuate nucleus: $\mathrm{Ca} 2+$ signaling via protein kinase $\mathrm{A}$ and $\mathrm{N}$-type channel-dependent mechanisms and cross-talk with leptin and orexin," Diabetes, vol. 52, no. 4, pp. 948-956, 2003.

[70] M. Lopez, R. Lage, A. K. Saha et al., "Hypothalamic fatty acid metabolism mediates the orexigenic action of ghrelin," Cell Metabolism, vol. 7, no. 5, pp. 389-399, 2008.

[71] L. Martins, D. Fernandez-Mallo, M. G. Novelle et al., "Hypothalamic mTOR signaling mediates the orexigenic action of ghrelin," PLoS One, vol. 7, no. 10, article e46923, 2012.

[72] D. Stevanovic, V. Trajkovic, S. Müller-Lühlhoff et al., "Ghrelin-induced food intake and adiposity depend on central mTORC1/S6K1 signaling," Molecular and Cellular Endocrinology, vol. 381, no. 1-2, pp. 280-290, 2013.

[73] Y. Minokoshi, Y. B. Kim, O. D. Peroni et al., "Leptin stimulates fatty-acid oxidation by activating AMP-activated protein kinase," Nature, vol. 415, no. 6869, pp. 339-343, 2002.

[74] L. L. Anderson, S. Jeftinija, and C. G. Scanes, "Growth hormone secretion: molecular and cellular mechanisms and in vivo approaches," Experimental Biology and Medicine (Maywood, N.J.), vol. 229, no. 4, pp. 291-302, 2004.

[75] Z. B. Andrews, Z. W. Liu, N. Walllingford et al., "UCP2 mediates ghrelin's action on NPY/AgRP neurons by lowering free radicals," Nature, vol. 454, no. 7206, pp. 846-851, 2008.

[76] K. Venkova and B. Greenwood-Van Meerveld, "Application of ghrelin to gastrointestinal diseases," Current Opinion in Investigational Drugs, vol. 9, no. 10, pp. 1103-1107, 2008.

[77] B. Kola and M. Korbonits, "Shedding light on the intricate puzzle of ghrelin's effects on appetite regulation," The Journal of Endocrinology, vol. 202, no. 2, pp. 191-198, 2009.

[78] C. T. Lim, B. Kola, and M. Korbonits, "AMPK as a mediator of hormonal signalling," Journal of Molecular Endocrinology, vol. 44, no. 2, pp. 87-97, 2010.

[79] C. Pemberton, P. Wimalasena, T. Yandle, S. Soule, and M. Richards, "C-terminal pro-ghrelin peptides are present in the human circulation," Biochemical and Biophysical Research Communications, vol. 310, no. 2, pp. 567-573, 2003.

[80] D. Cota, K. Proulx, K. A. Smith et al., "Hypothalamic mTOR signaling regulates food intake," Science, vol. 312, no. 5775, pp. 927-930, 2006.

[81] E. C. Villanueva, H. Munzberg, D. Cota et al., "Complex regulation of mammalian target of rapamycin complex 1 in the basomedial hypothalamus by leptin and nutritional status," Endocrinology, vol. 150, no. 10, pp. 4541-4551, 2009.

[82] W. Zhang, C. Zhang, D. Fritze, B. Chai, J. Li, and M. W. Mulholland, "Modulation of food intake by mTOR signalling in the dorsal motor nucleus of the vagus in male rats: 
focus on ghrelin and nesfatin-1," Experimental Physiology, vol. 98, no. 12, pp. 1696-1704, 2013.

[83] R. Lage, M. J. Vazquez, L. Varela et al., "Ghrelin effects on neuropeptides in the rat hypothalamus depend on fatty acid metabolism actions on BSX but not on gender," The FASEB Journal, vol. 24, no. 8, pp. 2670-2679, 2010.

[84] R. Avallone, A. Demers, A. Rodrigue-Way et al., "A growth hormone-releasing peptide that binds scavenger receptor CD36 and ghrelin receptor up-regulates sterol transporters and cholesterol efflux in macrophages through a peroxisome proliferator-activated receptor gamma-dependent pathway," Molecular Endocrinology, vol. 20, no. 12, pp. 3165-3178, 2006.

[85] D. Vats, L. Mukundan, J. I. Odegaard et al., "Oxidative metabolism and PGC-1beta attenuate macrophagemediated inflammation," Cell Metabolism, vol. 4, no. 1, pp. 13-24, 2006.

[86] J. Van den Bossche, J. Baardman, and M. P. de Winther, "Metabolic characterization of polarized M1 and M2 bone marrow-derived macrophages using real-time extracellular flux analysis," Journal of Visualized Experiments, vol. 1, no. 105, 2015.

[87] J. Van den Bossche, J. Baardman, N. A. Otto et al., "Mitochondrial dysfunction prevents repolarization of inflammatory macrophages," Cell Reports, vol. 17, no. 3, pp. 684-696, 2016.

[88] C. Chen, D. Wu, and I. J. Clarke, "Signal transduction systems employed by synthetic GH-releasing peptides in somatotrophs," The Journal of Endocrinology, vol. 148, no. 3, pp. 381-386, 1996.

[89] F. Zapata-Gonzalez, F. Rueda, J. Petriz et al., "9-cis-Retinoic acid (9cRA), a retinoid $\mathrm{X}$ receptor (RXR) ligand, exerts immunosuppressive effects on dendritic cells by RXRdependent activation: inhibition of peroxisome proliferatoractivated receptor gamma blocks some of the 9cRA activities, and precludes them to mature phenotype development," Journal of Immunology, vol. 178, no. 10, pp. 6130-6139, 2007.

[90] T. Sato, T. Ida, Y. Nakamura, Y. Shiimura, K. Kangawa, and M. Kojima, "Physiological roles of ghrelin on obesity," Obesity Research \& Clinical Practice, vol. 8, no. 5, pp. e405e413, 2014.

[91] F. M. Schmidt, J. Weschenfelder, C. Sander et al., "Inflammatory cytokines in general and central obesity and modulating effects of physical activity," PLoS One, vol. 10, no. 3, article e0121971, 2015.

[92] Y. E. Kang, J. M. Kim, K. H. Joung et al., “The roles of adipokines, proinflammatory cytokines, and adipose tissue macrophages in obesity-associated insulin resistance in modest obesity and early metabolic dysfunction," PLoS One, vol. 11, no. 4, article e0154003, 2016.

[93] K. Makki, P. Froguel, and I. Wolowczuk, "Adipose tissue in obesity-related inflammation and insulin resistance: cells, cytokines, and chemokines," ISRN Inflammation, vol. 2013, Article ID 139239, 12 pages, 2013.

[94] J. M. Olefsky and C. K. Glass, "Macrophages, inflammation, and insulin resistance," Annual Review of Physiology, vol. 72, pp. 219-246, 2010.

[95] S. L. Deshmane, S. Kremlev, S. Amini, and B. E. Sawaya, "Monocyte chemoattractant protein-1 (MCP-1): an overview," Journal of Interferon \& Cytokine Research, vol. 29, no. 6, pp. 313-326, 2009.
[96] W. G. Li, D. Gavrila, X. Liu et al., "Ghrelin inhibits proinflammatory responses and nuclear factor-kappaB activation in human endothelial cells," Circulation, vol. 109, no. 18, pp. 2221-2226, 2004.

[97] C. N. Lumeng, J. Liu, L. Geletka et al., "Aging is associated with an increase in T cells and inflammatory macrophages in visceral adipose tissue," Journal of Immunology, vol. 187, no. 12, pp. 6208-6216, 2011.

[98] J. Braune, U. Weyer, C. Hobusch et al., "IL-6 regulates M2 polarization and local proliferation of adipose tissue macrophages in obesity," Journal of Immunology, vol. 198, no. 7, pp. 2927-2934, 2017.

[99] L. Lin, J. H. Lee, E. D. Buras et al., "Ghrelin receptor regulates adipose tissue inflammation in aging," Aging (Albany NY), vol. 8, no. 1, pp. 178-191, 2016.

[100] A. Mantovani, S. K. Biswas, M. R. Galdiero, A. Sica, and M. Locati, "Macrophage plasticity and polarization in tissue repair and remodelling," The Journal of Pathology, vol. 229, no. 2, pp. 176-185, 2013.

[101] P. Peraldi, G. S. Hotamisligil, W. A. Buurman, M. F. White, and B. M. Spiegelman, "Tumor necrosis factor (TNF)-alpha inhibits insulin signaling through stimulation of the p55 TNF receptor and activation of sphingomyelinase," The Journal of Biological Chemistry, vol. 271, no. 22, pp. 1301813022, 1996.

[102] C. de Luca and J. M. Olefsky, "Inflammation and insulin resistance," FEBS Letters, vol. 582, no. 1, pp. 97-105, 2008.

[103] P. M. Moraes-Vieira, M. M. Yore, P. M. Dwyer, I. Syed, P. Aryal, and B. B. Kahn, "RBP4 activates antigen-presenting cells, leading to adipose tissue inflammation and systemic insulin resistance," Cell Metabolism, vol. 19, no. 3, pp. 512526, 2014.

[104] P. M. Moraes-Vieira, A. Castoldi, P. Aryal, K. Wellenstein, O. D. Peroni, and B. B. Kahn, "Antigen presentation and T-cell activation are critical for RBP4-induced insulin resistance," Diabetes, vol. 65, no. 5, pp. 1317-1327, 2016.

[105] S. P. Kalra, N. Ueno, and P. S. Kalra, "Stimulation of appetite by ghrelin is regulated by leptin restraint: peripheral and central sites of action," The Journal of Nutrition, vol. 135, no. 5, pp. 1331-1335, 2005.

[106] X. Ma, L. Lin, J. Yue et al., "Ghrelin receptor regulates HFCS-induced adipose inflammation and insulin resistance," Nutrition \& Diabetes, vol. 3, article e99, 2013.

[107] D. D. Taub, "Novel connections between the neuroendocrine and immune systems: the ghrelin immunoregulatory network," Vitamins and Hormones, vol. 77, pp. 325-346, 2008.

[108] C. Camell and C. W. Smith, "Dietary oleic acid increases M2 macrophages in the mesenteric adipose tissue," PLoS One, vol. 8, no. 9, article e75147, 2013.

[109] F. Ginhoux and S. Jung, "Monocytes and macrophages: developmental pathways and tissue homeostasis," Nature Reviews Immunology, vol. 14, no. 6, pp. 392-404, 2014.

[110] S. S. Choe, J. Y. Huh, I. J. Hwang, J. I. Kim, and J. B. Kim, "Adipose tissue remodeling: its role in energy metabolism and metabolic disorders," Frontiers in Endocrinology (Lausanne), vol. 7, p. 30, 2016.

[111] V. D. Dixit, E. M. Schaffer, R. S. Pyle et al., "Ghrelin inhibits leptin- and activation-induced proinflammatory cytokine expression by human monocytes and T cells," The Journal of Clinical Investigation, vol. 114, no. 1, pp. 57-66, 2004. 
[112] H. Wei, X. Cao, Q. Zeng et al., "Ghrelin inhibits proinflammatory responses and prevents cognitive impairment in septic rats," Critical Care Medicine, vol. 43, no. 5, pp. e143-e150, 2015.

[113] L. Chang, J. Zhao, J. Yang, Z. Zhang, J. Du, and C. Tang, "Therapeutic effects of ghrelin on endotoxic shock in rats," European Journal of Pharmacology, vol. 473, no. 2-3, pp. 171-176, 2003.

[114] A. Jacob, D. Rajan, B. Pathickal et al., "The inhibitory effect of ghrelin on sepsis-induced inflammation is mediated by the MAPK phosphatase-1," International Journal of Molecular Medicine, vol. 25, no. 1, pp. 159-164, 2010.

[115] S. Miyake and T. Yamamura, "Ghrelin: friend or foe for neuroinflammation," Discovery Medicine, vol. 8, no. 41, pp. 64-67, 2009.

[116] M. Ersahin, H. Z. Toklu, C. Erzik et al., "The antiinflammatory and neuroprotective effects of ghrelin in subarachnoid hemorrhage-induced oxidative brain damage in rats," Journal of Neurotrauma, vol. 27, no. 6, pp. 11431155, 2010.

[117] C. Liu, J. Huang, H. Li et al., "Ghrelin accelerates wound healing through GHS-R1a-mediated MAPK-NF-kappaB/ GR signaling pathways in combined radiation and burn injury in rats," Scientific Reports, vol. 6, article 27499, 2016.

[118] F. Azizzadeh, J. Mahmoodi, S. Sadigh-Eteghad, F. Farajdokht, and G. Mohaddes, "Ghrelin exerts analgesic effects through modulation of IL-10 and TGF-beta levels in a rat model of inflammatory pain," Iranian Biomedical Journal, vol. 21, no. 2, pp. 114-119, 2017.

[119] M. Granado, T. Priego, A. I. Martín, M. A. Villanúa, and A. López-Calderón, "Anti-inflammatory effect of the ghrelin agonist growth hormone-releasing peptide-2 (GHRP-2) in arthritic rats," American Journal of Physiology, Endocrinology and Metabolism, vol. 288, no. 3, pp. E486-E492, 2005.

[120] B. Li, M. Zeng, H. Zheng et al., "Effects of ghrelin on the apoptosis of human neutrophils in vitro," International Journal of Molecular Medicine, vol. 38, no. 3, pp. 794-802, 2016.

[121] T. Kodama, J. Ashitani, N. Matsumoto, K. Kangawa, and M. Nakazato, "Ghrelin treatment suppresses neutrophildominant inflammation in airways of patients with chronic respiratory infection," Pulmonary Pharmacology \& Therapeutics, vol. 21, no. 5, pp. 774-779, 2008.

[122] E. G. Orlova, S. V. Shirshev, and O. A. Loginova, "Leptin and ghrelin regulate dendritic cell maturation and dendritic cell induction of regulatory T-cells," Doklady Biological Sciences, vol. 462, pp. 171-174, 2015.

[123] V. D. Dixit, H. Yang, Y. Sun et al., "Ghrelin promotes thymopoiesis during aging," The Journal of Clinical Investigation, vol. 117, no. 10, pp. 2778-2790, 2007.

[124] J. Oh and J. S. Shin, "The role of dendritic cells in central tolerance," Immune Network, vol. 15, no. 3, pp. 111-120, 2015.

[125] L. Souza-Moreira, V. Delgado-Maroto, M. Morell, F. O'Valle, R. G. Del Moral, and E. Gonzalez-Rey, "Therapeutic effect of ghrelin in experimental autoimmune encephalomyelitis by inhibiting antigen-specific Th1/Th17 responses and inducing regulatory T cells," Brain, Behavior, and Immunity, vol. 30, pp. 54-60, 2013.

[126] S. D. Miller and W. J. Karpus, "Experimental autoimmune encephalomyelitis in the mouse," Current Protocols in Immunology, vol. 1, 2007, Chapter 15:Unit 151.
[127] M. M. Theil, S. Miyake, M. Mizuno et al., "Suppression of experimental autoimmune encephalomyelitis by ghrelin," Journal of Immunology, vol. 183, no. 4, pp. 2859-2866, 2009.

[128] L. L. Anderson, S. Jeftinija, C. G. Scanes et al., "Physiology of ghrelin and related peptides," Domestic Animal Endocrinology, vol. 29, no. 1, pp. 111-144, 2005.

[129] C. C. Au, M. M. Docanto, H. Zahid et al., "Des-acyl ghrelin inhibits the capacity of macrophages to stimulate the expression of aromatase in breast adipose stromal cells," The Journal of Steroid Biochemistry and Molecular Biology, vol. 170, pp. 49-53, 2017.

[130] T. Waseem, M. Duxbury, H. Ito, S. W. Ashley, and M. K. Robinson, "Exogenous ghrelin modulates release of pro-inflammatory and anti-inflammatory cytokines in LPS-stimulated macrophages through distinct signaling pathways," Surgery, vol. 143, no. 3, pp. 334-342, 2008.

[131] M. E. Bamberger, M. E. Harris, D. R. McDonald, J. Husemann, and G. E. Landreth, "A cell surface receptor complex for fibrillar beta-amyloid mediates microglial activation," The Journal of Neuroscience, vol. 23, no. 7, pp. 2665-2674, 2003.

[132] H. Jiang, L. J. Li, J. Wang, and J. X. Xie, "Ghrelin antagonizes MPTP-induced neurotoxicity to the dopaminergic neurons in mouse substantia nigra," Experimental Neurology, vol. 212, no. 2, pp. 532-537, 2008.

[133] M. Moon, H. G. Kim, L. Hwang et al., "Neuroprotective effect of ghrelin in the 1-methyl-4-phenyl-1,2,3,6-tetrahydropyridine mouse model of Parkinson's disease by blocking microglial activation," Neurotoxicity Research, vol. 15, no. 4, pp. 332-347, 2009.

[134] E. Lim, S. Lee, E. Li, Y. Kim, and S. Park, "Ghrelin protects spinal cord motoneurons against chronic glutamateinduced excitotoxicity via ERK1/2 and phosphatidylinositol3-kinase/Akt/glycogen synthase kinase-3beta pathways," Experimental Neurology, vol. 230, no. 1, pp. 114-122, 2011.

[135] Z. B. Andrews, D. Erion, R. Beiler et al., "Ghrelin promotes and protects nigrostriatal dopamine function via a UCP2dependent mitochondrial mechanism," The Journal of Neuroscience, vol. 29, no. 45, pp. 14057-14065, 2009.

[136] X. M. Guan, H. Yu, O. C. Palyha et al., "Distribution of mRNA encoding the growth hormone secretagogue receptor in brain and peripheral tissues," Brain Research. Molecular Brain Research, vol. 48, no. 1, pp. 23-29, 1997.

[137] J. M. Zigman, J. E. Jones, C. E. Lee, C. B. Saper, and J. K. Elmquist, "Expression of ghrelin receptor mRNA in the rat and the mouse brain," The Journal of Comparative Neurology, vol. 494, no. 3, pp. 528-548, 2006.

[138] V. Jackson-Lewis and S. Przedborski, "Protocol for the MPTP mouse model of Parkinson's disease," Nature Protocols, vol. 2, no. 1, pp. 141-151, 2007.

[139] Z. B. Andrews, S. Diano, and T. L. Horvath, "Mitochondrial uncoupling proteins in the CNS: in support of function and survival," Nature Reviews Neuroscience, vol. 6, no. 11, pp. 829-840, 2005.

[140] Z. B. Andrews, B. Horvath, C. J. Barnstable et al., "Uncoupling protein-2 is critical for nigral dopamine cell survival in a mouse model of Parkinson's disease," The Journal of Neuroscience, vol. 25, no. 1, pp. 184-191, 2005.

[141] B. Conti, S. Sugama, J. Lucero et al., "Uncoupling protein 2 protects dopaminergic neurons from acute 1,2,3,6-methyl- 
phenyl-tetrahydropyridine toxicity," Journal of Neurochemistry, vol. 93, no. 2, pp. 493-501, 2005.

[142] Z. B. Andrews, A. Rivera, J. D. Elsworth et al., "Uncoupling protein-2 promotes nigrostriatal dopamine neuronal function," The European Journal of Neuroscience, vol. 24, no. 1, pp. 32-36, 2006.

[143] H. Omrani, M. R. Alipour, F. Farajdokht, H. Ebrahimi, M. Mesgari Abbasi, and G. Mohaddes, "Effects of chronic ghrelin treatment on hypoxia-induced brain oxidative stress and inflammation in a rat normobaric chronic hypoxia model," High Altitude Medicine \& Biology, vol. 18, no. 2, pp. 145-151, 2017.

[144] V. P. Carlini, M. E. Monzon, M. M. Varas et al., "Ghrelin increases anxiety-like behavior and memory retention in rats," Biochemical and Biophysical Research Communications, vol. 299, no. 5, pp. 739-743, 2002.

[145] V. P. Carlini, M. Ghersi, H. B. Schiöth, and S. R. de Barioglio, "Ghrelin and memory: differential effects on acquisition and retrieval," Peptides, vol. 31, no. 6, pp. 11901193, 2010.

[146] S. Diano, S. A. Farr, S. C. Benoit et al., "Ghrelin controls hippocampal spine synapse density and memory performance," Nature Neuroscience, vol. 9, no. 3, pp. 381-388, 2006.

[147] V. P. Carlini, R. C. Gaydou, H. B. Schiöth, and S. R. de Barioglio, "Selective serotonin reuptake inhibitor (fluoxetine) decreases the effects of ghrelin on memory retention and food intake," Regulatory Peptides, vol. 140, no. 1-2, pp. 65-73, 2007.

[148] J. Altman and G. D. Das, “Autoradiographic and histological evidence of postnatal hippocampal neurogenesis in rats," The Journal of Comparative Neurology, vol. 124, no. 3, pp. 319335, 1965.

[149] J. A. Paton and F. N. Nottebohm, "Neurons generated in the adult brain are recruited into functional circuits," Science, vol. 225, no. 4666, pp. 1046-1048, 1984.

[150] G. L. Ming and H. Song, "Adult neurogenesis in the mammalian brain: significant answers and significant questions," Neuron, vol. 70, no. 4, pp. 687-702, 2011.

[151] D. A. Lee and S. Blackshaw, "Functional implications of hypothalamic neurogenesis in the adult mammalian brain," International Journal of Developmental Neuroscience, vol. 30, no. 8, pp. 615-621, 2012.

[152] R. A. Marr, R. M. Thomas, and D. A. Peterson, "Insights into neurogenesis and aging: potential therapy for degenerative disease?," Future Neurology, vol. 5, no. 4, pp. 527541, 2010.

[153] H. Jun, S. Mohammed Qasim Hussaini, M. J. Rigby, and M. H. Jang, "Functional role of adult hippocampal neurogenesis as a therapeutic strategy for mental disorders," Neural Plasticity, vol. 2012, Article ID 854285, 20 pages, 2012.

[154] K. S. Radad, R. Moldzio, M. Al-Shraim, B. Kranner, C. Krewenka, and W. D. Rausch, "Recent advances on the role of neurogenesis in the adult brain: therapeutic potential in Parkinson's and Alzheimer's diseases," CNS \& Neurological Disorders Drug Targets, vol. 16, 2017.

[155] A. Sahay, K. N. Scobie, A. S. Hill et al., "Increasing adult hippocampal neurogenesis is sufficient to improve pattern separation," Nature, vol. 472, no. 7344, pp. 466-470, 2011.

[156] M. Moon, S. Kim, L. Hwang, and S. Park, "Ghrelin regulates hippocampal neurogenesis in adult mice," Endocrine Journal, vol. 56, no. 3, pp. 525-531, 2009.
[157] W. Zhang, T. R. Lin, Y. Hu et al., "Ghrelin stimulates neurogenesis in the dorsal motor nucleus of the vagus," The Journal of Physiology, vol. 559, Part 3, pp. 729-737, 2004.

[158] I. Johansson, S. Destefanis, N. D. Aberg et al., "Proliferative and protective effects of growth hormone secretagogues on adult rat hippocampal progenitor cells," Endocrinology, vol. 149, no. 5, pp. 2191-2199, 2008.

[159] S. Wildman and A. Hewison, "Rediscovering a history of nursing management: from nightingale to the modern matron," International Journal of Nursing Studies, vol. 46, no. 12, pp. 1650-1661, 2009.

[160] H. Chung, E. Kim, D. H. Lee et al., "Ghrelin inhibits apoptosis in hypothalamic neuronal cells during oxygen-glucose deprivation," Endocrinology, vol. 148, no. 1, pp. 148-159, 2007.

[161] Y. Miao, Q. Xia, Z. Hou, Y. Zheng, H. Pan, and S. Zhu, "Ghrelin protects cortical neuron against focal ischemia/ reperfusion in rats," Biochemical and Biophysical Research Communications, vol. 359, no. 3, pp. 795-800, 2007.

[162] Y. Liu, L. Chen, X. Xu, E. Vicaut, and R. Sercombe, "Both ischemic preconditioning and ghrelin administration protect hippocampus from ischemia/reperfusion and upregulate uncoupling protein-2," BMC Physiology, vol. 9, p. 17, 2009.

[163] Y. Liu, P. S. Wang, D. Xie, K. Liu, and L. Chen, "Ghrelin reduces injury of hippocampal neurons in a rat model of cerebral ischemia/reperfusion," The Chinese Journal of Physiology, vol. 49, no. 5, pp. 244-250, 2006.

[164] J. C. Chuang and J. M. Zigman, "Ghrelin's roles in stress, mood, and anxiety regulation," International Journal of Peptide, vol. 2010, Article ID 460549, 5 pages, 2010.

[165] D. E. Cummings, D. S. Weigle, R. S. Frayo et al., "Plasma ghrelin levels after diet-induced weight loss or gastric bypass surgery," The New England Journal of Medicine, vol. 346, no. 21, pp. 1623-1630, 2002.

[166] E. Kristenssson, M. Sundqvist, M. Astin et al., "Acute psychological stress raises plasma ghrelin in the rat," Regulatory Peptides, vol. 134, no. 2-3, pp. 114-117, 2006.

[167] M. Lutter, I. Sakata, S. Osborne-Lawrence et al., "The orexigenic hormone ghrelin defends against depressive symptoms of chronic stress," Nature Neuroscience, vol. 11, no. 7, pp. 752-753, 2008.

[168] M. Ochi, K. Tominaga, F. Tanaka et al., "Effect of chronic stress on gastric emptying and plasma ghrelin levels in rats," Life Sciences, vol. 82, no. 15-16, pp. 862-868, 2008.

[169] G. M. Slavich and M. R. Irwin, "From stress to inflammation and major depressive disorder: a social signal transduction theory of depression," Psychological Bulletin, vol. 140, no. 3, pp. 774-815, 2014.

[170] R. Dantzer, J. C. O'Connor, G. G. Freund, R. W. Johnson, and K. W. Kelley, "From inflammation to sickness and depression: when the immune system subjugates the brain," Nature Reviews Neuroscience, vol. 9, no. 1, pp. 46-56, 2008.

[171] M. Alvarez-Crespo, K. P. Skibicka, I. Farkas et al., "The amygdala as a neurobiological target for ghrelin in rats: neuroanatomical, electrophysiological and behavioral evidence," PLoS One, vol. 7, no. 10, article e46321, 2012.

[172] R. M. Meyer, A. Burgos-Robles, E. Liu, S. S. Correia, and K. A. Goosens, "A ghrelin-growth hormone axis drives stressinduced vulnerability to enhanced fear," Molecular Psychiatry, vol. 19, no. 12, pp. 1284-1294, 2014.

[173] S. J. Spencer, T. L. Emmerzaal, T. Kozicz, and Z. B. Andrews, "Ghrelin's role in the hypothalamic-pituitary-adrenal axis 
stress response: implications for mood disorders," Biological Psychiatry, vol. 78, no. 1, pp. 19-27, 2015.

[174] M. G. Willesen, P. Kristensen, and J. Rømer, "Co-localization of growth hormone secretagogue receptor and NPY mRNA in the arcuate nucleus of the rat," Neuroendocrinology, vol. 70, no. 5, pp. 306-316, 1999.

[175] M. Milanski, G. Degasperi, A. Coope et al., "Saturated fatty acids produce an inflammatory response predominantly through the activation of TLR4 signaling in hypothalamus: implications for the pathogenesis of obesity," The Journal of Neuroscience, vol. 29, no. 2, pp. 359-370, 2009.

[176] J. P. Thaler, C. X. Yi, E. A. Schur et al., "Obesity is associated with hypothalamic injury in rodents and humans," The Journal of Clinical Investigation, vol. 122, no. 1, pp. 153-162, 2012.

[177] C. Andre, O. Guzman-Quevedo, C. Rey et al., "Inhibiting microglia expansion prevents diet-induced hypothalamic and peripheral inflammation," Diabetes, vol. 66, no. 4, pp. 908-919, 2017.

[178] S. Kalin, F. L. Heppner, I. Bechmann, M. Prinz, M. H. Tschöp, and C. X. Yi, "Hypothalamic innate immune reaction in obesity," Nature Reviews Endocrinology, vol. 11, no. 6, pp. 339-351, 2015.

[179] W. L. Reis, C. X. Yi, Y. Gao, M. H. Tschöp, and J. E. Stern, "Brain innate immunity regulates hypothalamic arcuate neuronal activity and feeding behavior," Endocrinology, vol. 156, no. 4, pp. 1303-1315, 2015.

[180] H. Cui, M. Lopez, and K. Rahmouni, "The cellular and molecular bases of leptin and ghrelin resistance in obesity," Nature Reviews Endocrinology, vol. 13, no. 6, pp. 338-351, 2017.

[181] K. El-Haschimi, D. D. Pierroz, S. M. Hileman, C. Bjørbaek, and J. S. Flier, "Two defects contribute to hypothalamic leptin resistance in mice with diet-induced obesity," The Journal of Clinical Investigation, vol. 105, no. 12, pp. 18271832,2000

[182] K. W. Williams, T. Liu, X. Kong et al., "Xbp1s in Pomc neurons connects ER stress with energy balance and glucose homeostasis," Cell Metabolism, vol. 20, no. 3, pp. 471-482, 2014.

[183] R. M. Ransohoff, P. Kivisakk, and G. Kidd, “Three or more routes for leukocyte migration into the central nervous system," Nature Reviews Immunology, vol. 3, no. 7, pp. 569$581,2003$.

[184] M. S. Kim, J. Yan, W. Wu, G. Zhang, Y. Zhang, and D. Cai, "Rapid linkage of innate immunological signals to adaptive immunity by the brain-fat axis," Nature Immunology, vol. 16, no. 5, pp. 525-533, 2015.

[185] S. H. Chang, C. R. Stoll, J. Song, J. E. Varela, C. J. Eagon, and G. A. Colditz, "The effectiveness and risks of bariatric surgery: an updated systematic review and meta-analysis, 2003-2012," JAMA Surgery, vol. 149, no. 3, pp. 275-287, 2014.

[186] B. Geloneze, M. A. Tambascia, V. F. Pilla, S. R. Geloneze, E. M. Repetto, and J. C. Pareja, "Ghrelin: a gut-brain hormone: effect of gastric bypass surgery," Obesity Surgery, vol. 13, no. 1, pp. 17-22, 2003.

[187] F. Leonetti, G. Silecchia, G. Iacobellis et al., "Different plasma ghrelin levels after laparoscopic gastric bypass and adjustable gastric banding in morbid obese subjects," The Journal of Clinical Endocrinology and Metabolism, vol. 88, no. 9, pp. 4227-4231, 2003.
[188] E. Lin, N. Gletsu, K. Fugate et al., "The effects of gastric surgery on systemic ghrelin levels in the morbidly obese," Archives of Surgery, vol. 139, no. 7, pp. 780-784, 2004.

[189] R. Morinigo, R. Casamitjana, V. Moizé et al., "Short-term effects of gastric bypass surgery on circulating ghrelin levels," Obesity Research, vol. 12, no. 7, pp. 1108-1116, 2004.

[190] M.T. Garcia-Unzueta, R. Fernandez-Santiago, A. DomínguezDíez, L. Vazquez-Salví, J. C. Fernández-Escalante, and J. A. Amado, "Fasting plasma ghrelin levels increase progressively after biliopancreatic diversion: one-year follow-up," Obesity Surgery, vol. 15, no. 2, pp. 187-190, 2005.

[191] F. B. Langer, M. A. Reza Hoda, A. Bohdjalian et al., "Sleeve gastrectomy and gastric banding: effects on plasma ghrelin levels," Obesity Surgery, vol. 15, no. 7, pp. 1024-1029, 2005.

[192] J. L. Chan, E. C. Mun, V. Stoyneva, C. S. Mantzoros, and A. B. Goldfine, "Peptide YY levels are elevated after gastric bypass surgery," Obesity (Silver Spring), vol. 14, no. 2, pp. 194-198, 2006.

[193] E. V. Kotidis, G. Koliakos, T. S. Papavramidis, and S. T. Papavramidis, "The effect of biliopancreatic diversion with pylorus-preserving sleeve gastrectomy and duodenal switch on fasting serum ghrelin, leptin and adiponectin levels: is there a hormonal contribution to the weight-reducing effect of this procedure?," Obesity Surgery, vol. 16, no. 5, pp. 554559, 2006.

[194] S. N. Karamanakos, K. Vagenas, F. Kalfarentzos, and T. K. Alexandrides, "Weight loss, appetite suppression, and changes in fasting and postprandial ghrelin and peptide-YY levels after Roux-en-Y gastric bypass and sleeve gastrectomy: a prospective, double blind study," Annals of Surgery, vol. 247, no. 3, pp. 401-407, 2008.

[195] E. Ram, T. Vishne, D. Diker et al., "Impact of gastric banding on plasma ghrelin, growth hormone, cortisol, DHEA and DHEA-S levels," Obesity Surgery, vol. 15, no. 8, pp. 11181123, 2005.

[196] B. Uzzan, J. M. Catheline, C. Lagorce et al., "Expression of ghrelin in fundus is increased after gastric banding in morbidly obese patients," Obesity Surgery, vol. 17, no. 9, pp. 1159-1164, 2007.

[197] J. M. Liou, J. T. Lin, W. J. Lee et al., "The serial changes of ghrelin and leptin levels and their relations to weight loss after laparoscopic minigastric bypass surgery," Obesity Surgery, vol. 18, no. 1, pp. 84-89, 2008.

[198] B. Olivan, J. Teixeira, M. Bose et al., "Effect of weight loss by diet or gastric bypass surgery on peptide YY3-36 levels," Annals of Surgery, vol. 249, no. 6, pp. 948-953, 2009.

[199] M. Faraj, P. J. Havel, S. Phélis, D. Blank, A. D. Sniderman, and K. Cianflone, "Plasma acylation-stimulating protein, adiponectin, leptin, and ghrelin before and after weight loss induced by gastric bypass surgery in morbidly obese subjects," The Journal of Clinical Endocrinology and Metabolism, vol. 88, no. 4, pp. 1594-1602, 2003.

[200] C. Holdstock, B. E. Engstrom, M. Ohrvall, L. Lind, M. Sundbom, and F. A. Karlsson, "Ghrelin and adipose tissue regulatory peptides: effect of gastric bypass surgery in obese humans," The Journal of Clinical Endocrinology and Metabolism, vol. 88, no. 7, pp. 3177-3183, 2003.

[201] G. Fruhbeck, F. Rotellar, J. L. Hernández-Lizoain et al., "Fasting plasma ghrelin concentrations 6 months after gastric bypass are not determined by weight loss or changes in insulinemia," Obesity Surgery, vol. 14, no. 9, pp. 12081215, 2004. 
[202] K. Schindler, G. Prager, T. Ballaban et al., "Impact of laparoscopic adjustable gastric banding on plasma ghrelin, eating behaviour and body weight," European Journal of Clinical Investigation, vol. 34, no. 8, pp. 549-554, 2004.

[203] R. Stoeckli, R. Chanda, I. Langer, and U. Keller, "Changes of body weight and plasma ghrelin levels after gastric banding and gastric bypass," Obesity Research, vol. 12, no. 2, pp. 346-350, 2004.

[204] M. Sundbom, C. Holdstock, B. E. Engström, and F. A. Karlsson, "Early changes in ghrelin following Roux-en-Y gastric bypass: influence of vagal nerve functionality?," Obesity Surgery, vol. 17, no. 3, pp. 304-310, 2007.

[205] B. A. Whitson, D. B. Leslie, T. A. Kellogg et al., "Enteroendocrine changes after gastric bypass in diabetic and nondiabetic patients: a preliminary study," The Journal of Surgical Research, vol. 141, no. 1, pp. 31-39, 2007.

[206] X. Chang, H. Yan, H. Bian et al., "Serum retinol binding protein 4 is associated with visceral fat in human with nonalcoholic fatty liver disease without known diabetes: a cross-sectional study," Lipids in Health and Disease, vol. 14, p. 28, 2015.

[207] H. Hosoda, K. Doi, N. Nagaya et al., "Optimum collection and storage conditions for ghrelin measurements: octanoyl modification of ghrelin is rapidly hydrolyzed to desacyl ghrelin in blood samples," Clinical Chemistry, vol. 50, no. 6, pp. 1077-1080, 2004.

[208] H. Hosoda and K. Kangawa, "Standard sample collections for blood ghrelin measurements," Methods in Enzymology, vol. 514, pp. 113-126, 2012.

[209] C. Compher and K. O. Badellino, "Obesity and inflammation: lessons from bariatric surgery," JPEN Journal of Parenteral and Enteral Nutrition, vol. 32, no. 6, pp. 645-647, 2008.

[210] B. D. Netto, S. C. Bettini, A. P. Clemente et al., "Roux-en-Y gastric bypass decreases pro-inflammatory and thrombotic biomarkers in individuals with extreme obesity," Obesity Surgery, vol. 25, no. 6, pp. 1010-1018, 2015.

[211] V. G. Sams, C. Blackledge, N. Wijayatunga et al., "Effect of bariatric surgery on systemic and adipose tissue inflammation," Surgical Endoscopy, vol. 30, no. 8, pp. 3499-3504, 2016.

[212] U. B. Pajvani, M. E. Trujillo, T. P. Combs et al., "Fat apoptosis through targeted activation of caspase 8: a new mouse model of inducible and reversible lipoatrophy," Nature Medicine, vol. 11, no. 7, pp. 797-803, 2005. 


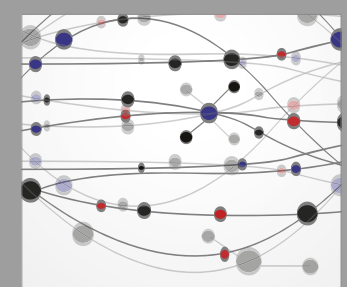

The Scientific World Journal
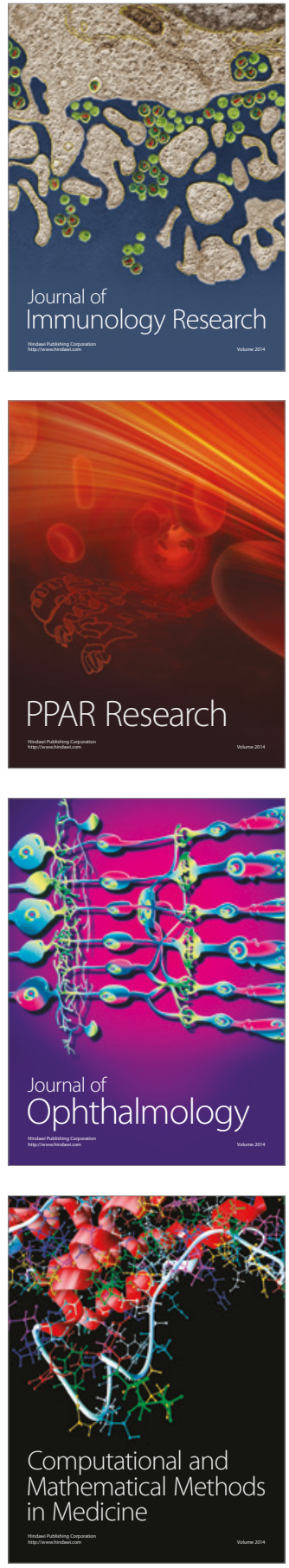

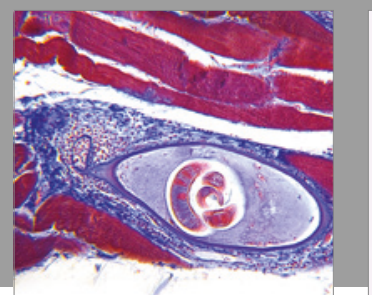

Gastroenterology Research and Practice
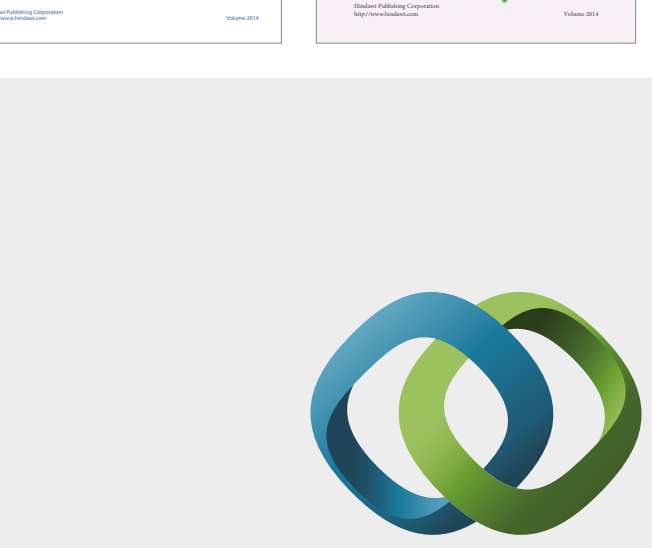

\section{Hindawi}

Submit your manuscripts at

https://www.hindawi.com
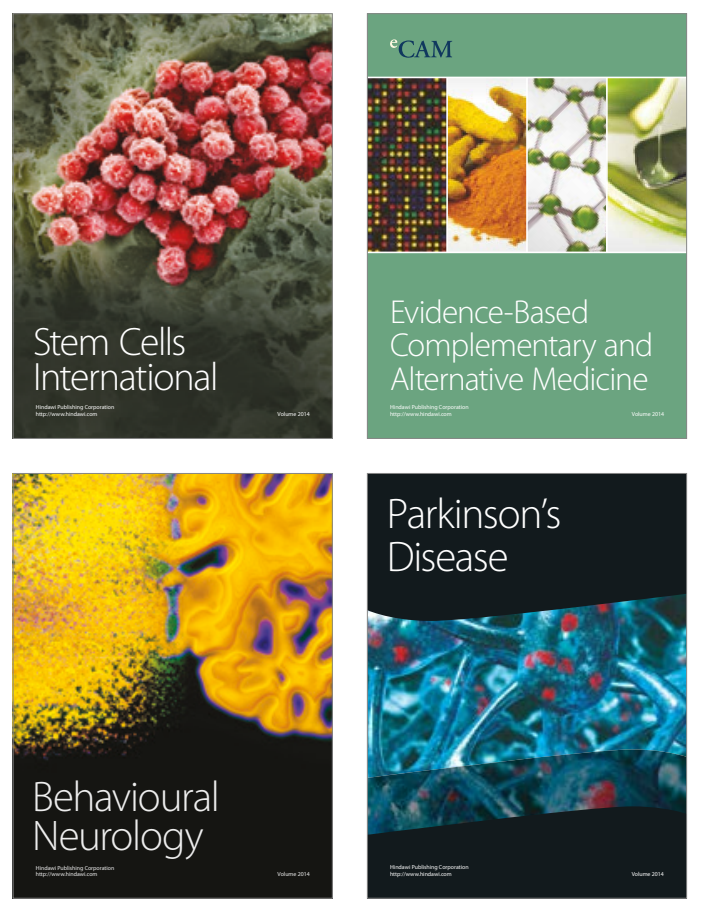
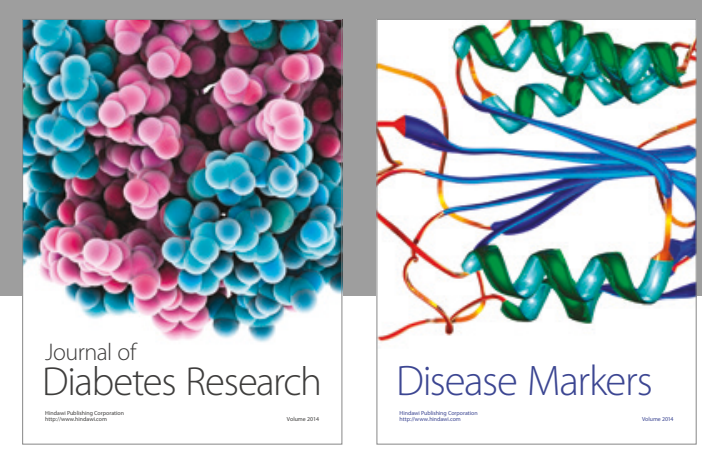

Disease Markers
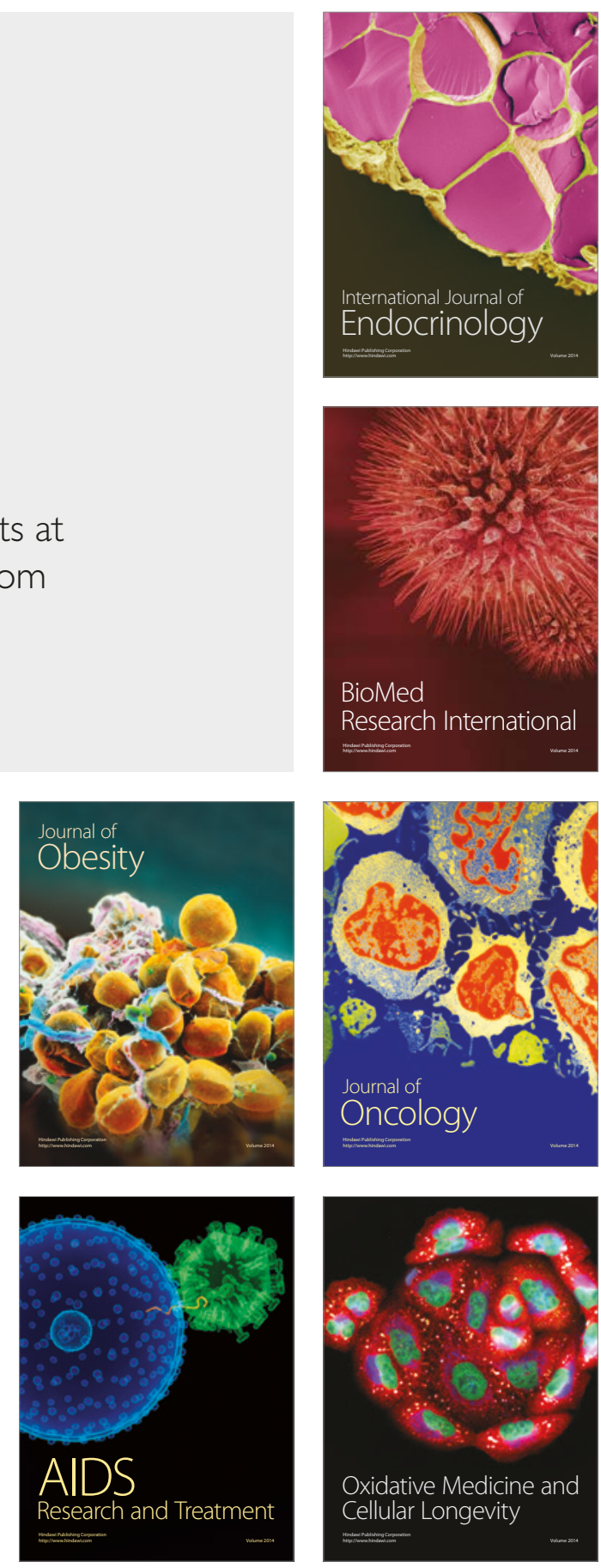